\title{
Comparing the Effectiveness of Employment Subsidies
}

\author{
Alessio J. G. Brown ${ }^{\mathrm{a}}$, Christian Merkl ${ }^{\mathrm{a}}$ and Dennis J. Snower ${ }^{\mathrm{a}}$ \\ ${ }^{a}$ The Kiel Institute for the World Economy and Christian-Albrechts-University, Kiel
}

02 November 2006

\begin{abstract}
This paper provides a theoretical and quantitative analysis of various types of wellknown employment subsidies. Two important questions are addressed: (i) How should employment subsidies be targeted? (ii) How large should the subsidies be? We consider measures involving targeting workers with low incomes/abilities and targeting the unemployed.

To make our analysis particularly useful to policy makers, we focus on policies that are "approximately welfare efficient," i.e. policies that (a) improve employment and welfare, (b) do not raise earnings inequality and (c) are self-financing. This criterion enables us to identify policies which satisfy these favorable properties and to determine the size of the subsidies required for this purpose.

We construct a simple, dynamic model of hiring and separations, derived from microfoundations, and calibrate it with German data. The calibration shows that hiring vouchers targeted at the long-term unemployed and low-income/ability workers can be approximately welfare efficient, while low-wage subsidies do not satisfy this criterion. Even in terms of inequality reduction low-wage subsidies are outperformed by targeted hiring vouchers. Furthermore, hiring vouchers targeted at the long-term unemployed are more effective than hiring vouchers targeted at low-income/ability workers. These subsidy rankings also hold if the self-financing constraint is relaxed and the government spends a given additional amount on the subsidies.
\end{abstract}

Keywords: low wage subsidy; hiring voucher; targeting; employment; unemployment; duration; self-financing;

JEL classification: J23, J24, J38, J64, J68

Address:

The Kiel Institute for the World Economy

Duesternbrooker Weg 120

24105 Kiel

Germany
Telephone: +49431 8814-235

Fax: +49 $4318814-501$

E-Mail: alessio.brown@ifw-kiel.de christian.merkl@ifw-kiel.de dennis.snower@ifw-kiel.de 


\section{$1 \quad$ Introduction $^{1}$}

This paper aims to provide a groundwork for comparing the effectiveness of alternative employment subsidy policies. In doing so, we attempt to make our analysis maximally useful to the decisions that policy makers commonly face in practice.

We focus on employment subsidies because these policies are often meant to reduce both unemployment and earnings inequality together. The quest for such measures has been a prime objective of employment policy throughout the OECD and continues to be central to the policy debate in the large continental European countries. ${ }^{2}$

To make our analysis expressly relevant to policy making, we do not follow the mainstream practice of deriving policies as first-best responses to market failures; rather we begin with a model that covers a variety of common labor market imperfections - insider wage bargaining, hiring and firing costs, and imperfections related to the tax and transfer system - and examine the second-best employment policy response, taking these imperfections as given. We assume, as policy makers often do, that the institutions underlying these imperfections can be changed only gradually and with considerable delay; and thus we argue that it is useful to examine the relative effectiveness of different employment policies while these institutions are in place. Furthermore, in accord with policy makers' actual concerns, we measure policy effectiveness not just in terms of employment and welfare, but also give explicit consideration to earnings inequality and government budgetary outlays.

Due to the labor market imperfections above, the resulting unemployment can be inefficient. Our analysis is appropriate to policy design in high-unemployment countries, such as Germany, where policy makers have every reason to believe that unemployment is in fact inefficiently high. Then, in principle, employment policies may make some people better off without making others worse off.

It is well known that identifying such Pareto welfare-improving policies is insuperably difficult in practice. Thus our analysis focuses on policies that are "approximately Pareto welfare efficient" - or simply approximately welfare efficient, for short - in the following sense:

1. they improve aggregate employment and welfare (defined in terms of the utility functions of the households),

2. they do not increase earnings inequality (measured in terms of the Gini coefficient), and

3. they are self-financing (i.e. they do not require an additional government budgetary allocation).

Clearly, approximate welfare efficiency is not equivalent to Pareto welfare efficiency, because an employment policy can obviously satisfy the three conditions above and still generate uncompensated losers. Nevertheless, we argue that approximate welfare efficiency is a useful concept for policy making, since policies that are approximately welfare efficient are not only desirable for Benthamite reasons (the greatest happiness of the greatest number of people), but are unlikely to be blocked through the political process (since the fear of rising earnings inequality is the most common reason for blocking efficiency-improving employment reforms). ${ }^{3}$

The design of employment policies in most OECD countries indeed reflects governments' need to address both equity and efficiency objectives. The inefficiency of passive unemployment

\footnotetext{
${ }^{1}$ We thank Gert Pönitzsch, Ellen Schmieder, and Mariana Heinrich for excellent research assistance. Furthermore, we are very grateful to Ralf Wilke for providing us details on micro-econometric labor studies for Germany.

${ }^{2}$ For a detailed discussion of currently applied employment subsidy programs in Germany and recent reform proposals see Boss (2006).

${ }^{3}$ See, for example, Orszag and Snower (1998), Saint Paul (1995, 1996 and 1998).
} 
policies - such as the payment of tax-financed unemployment benefits to those who are jobless is generally due to policy makers' attempt to satisfy equity objectives. Both the unemployment benefits and the taxes that finance them generate externalities: the recipients get an uncompensated benefit, while the tax payers have an uncompensated cost. Thus the work-leisure choice is distorted. The widespread move from passive to active labor market policies is usually motivated by the need to reduce such inefficiencies. Some active labor market policies however appear to have improved employment incentives at the expense of income equality. ${ }^{4}$ Against this backdrop, it appears useful to identify policies that increase employment and welfare without raising income inequality.

This paper addresses two important questions: (i) How should employment policies be targeted? (ii) What should the magnitude of the policy intervention be? There is much disagreement on these issues among policy makers.

In practice, there are two broad policy approaches to targeting: The first favors targeting workers with low incomes and low abilities; and the second focuses on targeting the unemployed. Within each of these approaches, there is a plethora of more detailed choices to be made. ${ }^{5}$ Specifically, this paper compares the effectiveness of the following employment subsidy policies: (i) wage subsidies targeted at workers with low abilities, (ii) hiring vouchers targeted at longterm unemployed workers, (iii) hiring vouchers targeted at workers with low abilities, and (iv) hiring vouchers targeted at long-term unemployed workers with low abilities.

We address the issue of targeting by examining how much additional employment and social welfare each employment subsidy policy creates. To analyze the desirable magnitude of the policy intervention, we make use of the concept of approximate welfare efficiency. Specifically, we examine how large each particular employment subsidy can become before it ceases to be approximately welfare efficient (AWE). In our analysis, the policies under consideration exhibit "diminishing returns," in the sense that equal incremental increases in each employment subsidy leads to progressively smaller incremental increases in employment and social welfare and a progressively larger government budgetary outlay. We show that, for each employment subsidy, once a critical level is exceeded, it ceases to be self-financing. Recalling that our notion of approximate welfare efficiency involves the satisfaction of three constraints - an employment and welfare constraint, an earnings inequality constraint, and a self-financing constraint - we find, in our calibration exercises, that as each subsidy is increased, the self-financing constraint is reached first. Thus the self-financing constraint determines the magnitude of each policy intervention that is compatible with approximate welfare efficiency.

On this basis, we then compare the effectiveness of alternative employment subsidy policies. Our notion of policy effectiveness is related to a policy's ability to raise employment and welfare, while remaining AWE. The more an approximately welfare efficient policy raises employment and welfare, the more "effective" we denote the policy to be.

Our analysis tackles these issues by presenting a model that is rich enough to capture the various groups of workers relevant to these alternative targeting approaches, while at the same time being simple enough to generate straightforward policy guidelines. We calibrate

\footnotetext{
${ }^{4}$ See, for example, Grogger and Karoly (2005).

${ }^{5}$ For example, if workers with low incomes are the focus, how narrowly should they be targeted? (Should employment-promoting policies be directed mainly, say, at the lowest decile or the lowest quintile?) How should the magnitude of the policy intervention depend on incomes? (For instance, should the employment subsidy or tax rebate rise as income falls, or should the profile be hump-shaped, as for the U.S. Earned Income Tax Credit?) If unemployed workers are the target group, then how narrowly should the policy be targeted at the long-term unemployed and how should the magnitude of the employment-promoting intervention depend on the duration of unemployment? Alternatively, should the policy be targeted at young or old unemployed people, and if so, how?

Beyond that, the two approaches could be combined. The policy could, for example, be targeted at low-skilled, unemployed workers. If so, what should be the relative importance of skills versus unemployment duration in the policy targeting scheme?
} 
the model for the German labor market, which has characterized by high aggregate and longterm unemployment over the past three decades, and we then derive the corresponding policy implications.

We show that, for the calibrated model, a hiring voucher targeted at the long-term unemployed is particularly effective in raising employment and welfare, without reducing income inequality or requiring an additional government budget outlay. (In fact, as noted, the employment- and welfare-maximizing AWE subsidy reduces earnings inequality.) Furthermore, we find that hiring vouchers targeted at the duration of unemployment are more effective in raising employment and welfare than those targeted at unskilled (low-ability) workers. Moreover, while low wage subsidies can also reduce income inequality, they are a relatively expensive and ineffective instrument for reducing unemployment. These are striking results.

We also investigate the employment and equity effects of implementing employment subsidies in excess of the magnitudes that are self-financing. Specifically, we examine how much employment could be created by each of the policy measures under consideration if the government's net bugetary allocation for this measures were increased by a specified amount. Here, too, we find that hiring vouchers targeted at the long-term unemployed have relatively strong employment creating effects, without inequality implications. Subsidies targeted at low-ability workers turn out to be less effective.

The paper is organized as follows. Section 2 provides some background to our analysis. Section 3 presents our theoretical model of the labor market. Section 4 calibrates this model for Germany, shows the driving effects to make a policy effective and derives the policy implications. Finally, Section 5 concludes.

\section{Background}

\subsection{The Two Great Divides}

Our analysis deals with the "two great divides" that separate the haves from the have-nots in the labor market: (i) the divide between employment and unemployment and (ii) the divide between high-wage and low-wage jobs. The first divide is central to the employment policy debate in Europe, while the second receives relatively more attention in the United States.

Both divides may be inefficient and inequitable. Unemployment and working poverty are obvious sources of income inequality. These problems may also reflect inequality of opportunity if the incentives to work and search for jobs are unequally distributed among the working population. Furthermore, unemployment and working poverty are inefficient when incentives for work, job search, and human capital acquisition have been distorted. For these reasons these problems become legitimate objects of government policies. A wide variety of employment policy instruments have been used for this objective: income taxes and income tax credits, wage subsidies, hiring vouchers, in-kind benefits, and so on. For the purposes of our paper, we are concerned only with the effect of these policy instruments on incentives in the labor market; different policies that create the same incentives will be indistinguishable in our model. On this account, we will denote all these instruments as "employment subsidies," in the sense that they promote employment by altering the incentives of labor market participants. The central issues of the paper are how to target these subsidies and how large the subsidies should be.

The two divides are not completely separate phenomena. For example, long-term unemployment can lead to skill attrition, lower productivity, and thereby to low-wage jobs. Low-wage jobs are frequently associated with relatively high labor turnover and thus the low-wage job holders often become relatively prone to unemployment. Thus both of the above policy approaches those targeted at low incomes/skills and those targeted at the unemployed - will affect both unemployment and working poverty. On this account, we will analyze both problems within 
the same analytical framework.

Some commentators ${ }^{6}$ have noted that, with regard to individual welfare, there is often little to distinguish the unemployed in Europe from the working poor in the US. Both groups tend to have relatively low living standards. With regard to the economy's productive potential, however, there may be significant differences. The working poor produce goods and services, whereas the unemployed do not. Moreover, the unemployed impose costs on the rest of society since their unemployment benefits and related welfare entitlements are paid largely by employers and employees, as are some of the crime and health costs generated by the unemployed whereas the working poor tend to do so only to a lesser degree. Beyond that, the unemployed suffer depreciation of their human capital, whereas the working poor may gain human capital, possibly in terms of work habits and contacts to employment opportunities. ${ }^{7}$ These phenomena are captured by our model.

In our model, differences in productivity among workers are due to both differences in ability and differences in unemployment duration (via skill attrition). This distinction is important, since ability and unemployment duration differ in their amenability to policy influence. In practice, unemployment duration is readily affected through the standard employment policy instruments, whereas ability can be affected primarily though education and training policy and this influence takes a comparatively long-time to manifest itself. Since our focus is on employment policy, we let the unemployment duration-dependent productivity differences be endogenous (influenceable by the policy), whereas the ability-dependent productivity differences are defined as exogenous (not influenceable by the policy). ${ }^{8}$

\subsection{Relation to the Literature}

There is a large theoretical and empirical literature on the impact and optimal design of employment subsidies, originated with the work by Pigou (1933) and Kaldor (1936). ${ }^{9}$

Frequently, the Mortensen's and Pissarides' (1994) search and matching framework is used to analyze the effect of employment subsidies (see e.g. Boone and van Ours (2004), Bovenberg et al. (2000), Cardullo and van der Linden (2006), Mortensen and Pissarides (2003), Pierrard (2005), and Vereshchagina (2002)). The matching technology - describing the relation between the inputs and output of the matching process - is assumed to be stable through time. This assumption is admissible provided that the matching technology (described by the functional form of the matching function) can be considered independent of the inputs and output of the matching process. However, very often a negative time trend is found when estimating the search and matching function, thus casting doubt on the stability through time (Blanchard and Diamond (1989) for the United States, and Fahr and Sunde $(2001,2004)$ for Germany). ${ }^{10}$ It is admissible to use the matching function to analyze labor market policies, provided that these

\footnotetext{
${ }^{6}$ See, for example, Krugman (1994) and Freeman (1995).

${ }^{7}$ Naturally, these differences must not be overplayed. The productivity of the working poor is often low and thus their output of goods and services, relative to the voluntary and informal work of the unemployed, is accordingly limited. Furthermore, as governments throughout the OECD have begun to shift from passive to active labor market measures, so the costs that the working poor impose on the rest of society have risen and the corresponding costs of the unemployed have fallen.

${ }^{8}$ Our analysis can be extended to education and training policy; see, for example, Oskamp and Snower (2006).

${ }^{9}$ For a survey of the empirical literature, see for example Katz (1998). For US evidence, see Woodbury and Spiegelman (1987) and O'Leary et al. (2006). For international evidence, see for example N.E.R.A. (1995), and for British evidence, see Bell et al. (1999). As follows, we will focus on theoretical papers and the calibration thereof.

${ }^{10}$ Furthermore, many empirical studies reject the hypothesis of constant returns to scale (e.g. Warren (1996) for the United States, Fahr and Sunde (2001) for Germany). The number of matches $(M)$ is a function of unemployment and vacancies $(M=f(U, V))$, typically specified in Cobb Douglas form $\left(M=U^{\alpha} V^{\beta}\right)$. If $\alpha+\beta$ do not sum up to 1 , the results are input dependent.
} 
policies have no significant influence on the matching process itself. However, we do not see a rationale why active labor market policies should not affect the matching process.

To prevent running afoul of the Lucas Critique, we do not take the aforementioned shortcut. $^{11}$ Instead, we derive the policy effects in a microfounded way from the intertemporal maximization of economic agents and model their incentives explicitly. We give special emphasis to the firm side in our model since labor demand is the short side of the market in economies with stellar unemployment. The household side comes into play through the wage formation.

Many theoretical analyses are static and thus suffer from the serious drawback that they capture only short-run impact effects of employment policy. ${ }^{12}$ There are however good theoretical and empirical reasons to believe that longer-run effects are important, often more important than the short-run effects. ${ }^{13}$ (There are various significant dynamic interconnections. For example, hiring in response to employment policy takes time and may have persistent effects since incumbent employees' probability of being retained generally exceeds the unemployed people's probability of being hired.) We explicitly capture the dynamic effects of subsidies by specifying the transition rates between employment and unemployment as a function of the employment incentives of the firm.

We contribute to the existing literature by considering, as noted, skills depending unemployment duration as well as on different levels of ability. This detailed grid allows us to analyze and contrast the effects of employment subsidies targeted at different skill classes under the criteria approximative welfare efficiency - explicitly taking the complete budgetary effects into account. ${ }^{14}$

This is in stark contrast to the existing literature which only considers a small subset of possible targets for employment subsidies. A large part examines the rationale and economic effects of subsidies for the low skilled (e.g., Phelps (1994, 1997a, 1997b), Drèze and Snessens (1997), and Oskamp and Snower (2006) $)^{15}$, while less attention has been given to subsidies to long-term unemployed workers (Hui and Trivedi (1986), Snower (1994), Vereshchagina (2002)).

We now proceed to present how these heterogeneities are modelled in our analytical framework.

\section{The Model}

We construct a Markov model of the labor market in which the dynamics of employment and unemployment is determined by transition probabilities among various labor market states. We derive these transition probabilities from optimization principles.

As noted, our model is meant to be both rich enough to capture unemployment-duration dependent and ability-dependent skills, but it also aims to be simple enough to generate straightforward, intuitively transparent, policy guidelines. Accordingly, our model involves some judicious compromises between analytical simplicity and the depiction of heterogeneous labor market behaviors.

\footnotetext{
${ }^{11}$ Furthermore, in contrast to a big part of the search and matching literature, we use an endogenous job destruction rate. It can e.g. be expected that a wage subsidy reduces the firing rate, while a hiring subsidy does not do so. Omitting this feature would bias the results.

${ }^{12}$ See, e.g., Layard et al. (1991), pp. 490-492, and Snower (1994).

${ }^{13}$ Orszag and Snower (2000) have shown that the dynamic, long-run effects of employment subsidies, once the associated lagged adjustment processes have worked themselves out, differ from what may be expected in the short run.

${ }^{14}$ Orszag and Snower (2003a and 2003b) pointed out the fact that the literature disregarded the complete impact of employment subsidies on the government budget constraint by requiring that aggregate payroll taxes finance aggregate employment subsidies and thereby ignoring the reduction of unemployment benefit payments, which result from reduced employment. In this paper we follow their line of reasoning.

${ }^{15}$ Mortensen and Pissarides (2003) analyze low wage and hiring subsidies, but do not take different unemployment durations into account.
} 
Specifically, our model contains workers in three ability classes: low-ability, medium-ability and high-ability workers, denoted by $\alpha=l, m, h$, respectively. These ability classes can be interpreted as the exogenous component of skill differences, specifically, exogenous with respect to the employment policies under consideration in this paper. Within each ability class, there are workers in five labor market states:

1. the long-term unemployed $\left(U^{L}\right)$, who have been unemployed for more than a year (the period of analysis),

2. the short-term unemployed $\left(U^{S}\right)$, who have been unemployed up to one year,

3. the primary entrants $\left(N^{E 1}\right)$, who are short-term employed workers (employed up to one year) that were previously short-term unemployed,

4. the secondary entrants $\left(N^{E 2}\right)$, who are short-term employed workers that were previously long-term unemployed, and

5. the insiders $\left(N^{I}\right)$, who are long-term employed, i.e. employed for more than a year.

We assume that insiders are more productive than primary entrants who, in turn, are more productive than secondary entrants. (The terms "primary" and "secondary" are taken from the literature on dual labor markets ${ }^{16}$, where workers in the primary sector are more productive than those in the secondary sector.) Our model describes labor market activity for workers in each ability class as a Markov process involving these five states. The transition probabilities among these states are derived from microeconomic foundations. As noted, we treat the ability classes as exogenous with respect to employment policy, and thus we assume that there are no transitions among these ability classes. ${ }^{17}$

In sum, workers in our model occupy three ability classes $(\alpha=h, m, l$, i.e. low, medium, and high ability) and three duration-dependent classes, if employed $\left(d_{n}=I, E 1, E 2\right.$, i.e. insiders, primary entrants and secondary entrants), or two duration-dependent classes, if unemployed $\left(d_{u}=S\right.$, L, i.e. short-term and long-term unemployed). We assume constant returns to labor. Let $a_{\alpha}^{d_{n}}$ be the labor productivity of an employee in duration class $d_{n}$ and ability class $\alpha .{ }^{18}$ The firm faces a random $\operatorname{cost} \varepsilon_{\alpha, t}$, which is iid across workers and time within the ability class $\alpha$. This cost may be interpreted as, say, an operating cost or a negative productivity shock. Its mean is normalized to zero and its cumulative distribution $\Gamma_{\alpha}\left(\varepsilon_{\alpha}\right)$ is time-invariant.

Agents in our model pursue the following sequence of decisions. First the government sets the income tax rate to ensure that its tax receipts are equal to its net budgetary allocation on employment subsidies. Second, wages are determined through bargaining. Third, the random operating costs are revealed and then employment decisions are made.

\subsection{The Government Budget Constraint}

For simplicity, our model considers only four instruments of government policy: (i) a payroll tax, with a tax rate $\tau$, (ii) an unemployment benefit $b_{\alpha, t}$, (iii) an employment subsidy, specifically a hiring voucher $\sigma_{\alpha, t}^{d_{u}}$ targeted at workers of duration-dependend groups and ability-dependent groups or a wage subsidy $\sigma_{\alpha, t}$ for employees of certain abilities $\alpha$, and (iv) the net allocation of government expenditures $G_{t}$ to employment subsidies.

The government budget is given by

\footnotetext{
${ }^{16}$ See e.g. Dickens and Lang (1988).

${ }^{17}$ With respect to training policy, these ability classes would become endogenous, as in Oskamp and Snower (2006).

${ }^{18}$ We follow the notational convention that only those variables have time subscripts that actually vary through time in our model.
} 


$$
G_{t}+\sum_{\alpha} n_{\alpha, t} l_{\alpha} w_{\alpha, t} \tau=\sum_{\alpha} \sum_{d_{u}} u_{\alpha, t}^{d_{u}} l_{\alpha} b_{\alpha, t}+\sum_{\alpha} \sum_{d_{u}} \sigma_{\alpha, t}^{d_{u}} u_{\alpha, t}^{d_{u}} l_{\alpha} \eta_{\alpha, t}^{d_{u}}+\sum_{\alpha} \sigma_{\alpha, t} l_{\alpha} n_{\alpha, t}
$$

For simplicity, our model has only one tax: a proportional payroll tax paid by employed workers. This tax rate $\tau$ balances the government budget in absence of subsidies (i.e., $\sigma_{\alpha, t}=\sigma_{\alpha, t}^{d_{u}}=0$ and $\left.G_{t}=0\right)$, thereby finances payments of the unemployment benefit $b_{\alpha, t}$ to all short-term and long-term unemployed workers.

We take the net allocation of government expenditures $G_{t}$ to employment subsidies as exogenously given. The gross allocation of government expenditures is equal to the total amount that the government spends on employment subsidies. If these subsidies create employment, then they generate subsidy-induced revenue for the government, by leading to a fall in the number of people requiring unemployment benefits and an increase in the number of people paying taxes. The net allocation of government expenditures $G_{t}$ is equal to the gross allocation minus the subsidy-induced revenue. ${ }^{19}$ When $G_{t}=0$, the government budget on employment subsidies is balanced, employment subsidies are self-financing.

\subsection{Wage Determination}

For simplicity, let the wage $w_{\alpha}$ for each ability class $\alpha$ be the outcome of a Nash bargain between the median insider of that ability class and her firm. The median insider faces no risk of dismissal at the negotiated wage. ${ }^{20}$ The wage is renegotiated in each period $t$. Each worker has the following utility function:

$$
v_{t}(c)=c_{t}^{\xi}
$$

which depends positively on consumption $c_{t} \cdot{ }^{21}$ Under bargaining agreement, the insider receives the wage $w_{\alpha, t}(1-\tau)$, where $\tau$ is the payroll tax rate, and the firm receives the expected profit $\left(a_{\alpha}^{I}-w_{\alpha, t}\right)$ in each period $t$. Thus the expected present value of the insider's utility $V_{\alpha, t}^{I}$ under bargaining agreement is

$$
V_{\alpha, t}^{I}=\left(w_{\alpha, t}(1-\tau)\right)^{\xi}+\delta\left(\left(1-\phi_{\alpha, t+1}\right) V_{\alpha, t+1}^{I}+\phi_{\alpha, t+1} V_{\alpha, t+1}^{S}\right)
$$

where $\phi_{\alpha, t+1}$ is the firing rate and $V_{\alpha, t+1}^{S}$ the expected present value of a short-term unemployed workers' returns. The expected present value of firm's returns under bargaining agreement are

$$
\Pi_{\alpha, t}^{I}=\left(a_{\alpha}^{I}-w_{\alpha, t}+\sigma_{\alpha}\right)+\delta\left(\left(1-\phi_{\alpha, t+1}\right) \Pi_{\alpha, t+1}^{I}-\phi_{\alpha, t+1} f_{\alpha, t+1}\right)
$$

where $f_{\alpha, t+1}$ are firing costs.

\footnotetext{
${ }^{19}$ Along these lines, the net allocation of government expenditures to employment subsidies can be calculated as $G_{t}=\sum_{\alpha} \sum_{d_{u}} \sigma_{\alpha, t}^{d_{u}} u_{\alpha, t}^{d_{u}} l_{\alpha} \eta_{\alpha, t}^{d_{u}}+\sum_{\alpha} \sigma_{\alpha, t} l_{\alpha} n_{\alpha, t}-\left(\Delta_{t} \sum_{\alpha} n_{\alpha, t} l_{\alpha} w_{\alpha, t} \tau_{t}-\Delta_{t} \sum_{\alpha} \sum_{d_{u}} u_{\alpha, t}^{d_{u}} l_{\alpha} b_{\alpha, t}\right)$, where $\Delta_{t}$ denotes the change in the respective revenue/expenditure.

${ }^{20}$ These assumptions are made merely for analytical convenience; various other assumptions would lead to similar results. For example, we could assume that the wage in each sector is determined through bargaining between an insider and her firm in that sector, and that the trapped workers have a higher replacement ratio than the primary workers. The net replacement rates (unweighted average across six family types) of workers with 67, 100, and 150 percent of average productivity are 78.25, 68.25, and 64.67 percent, respectively (see Appendix A.2.1, OECD (2006)).

Alternatively, the wage could be determined through bargaining between the firm and a sector-specific or economy-wide union that represents the senior workers (i.e. workers who do not face a risk of dismissal at the bargained wage). Finally, the wage could be the outcome of a bargain between the firm and the marginal worker, or between the firm an a union representing all employees. In this last case, the insiders' objective in the bargain will depend on their retention rate.

${ }^{21}$ In our model, for simplicity, workers consume all their income.
} 
Under disagreement, the insider's fallback income is $b_{\alpha, t}$, assumed for simplicity to be equal to the unemployment benefit. The firm's fallback profit is $-f_{\alpha, t}$, i.e. during disagreement the insider imposes the maximal cost on the firm (e.g. through strike, work-to-rule, sabotage) short of inducing dismissal. Assuming that disagreement in the current period does not affect future returns, the present values of utility under disagreement for the insider are

$$
V_{\alpha, t}^{I I}=\left(b_{\alpha, t}\right)^{\xi}+\delta\left(\left(1-\phi_{\alpha, t+1}\right) V_{\alpha, t+1}^{I}+\phi_{\alpha, t+1} V_{\alpha, t+1}^{S}\right)
$$

and for the firm are

$$
\Pi_{\alpha, t}^{\prime I}=-f_{\alpha, t}+\delta\left(\left(1-\phi_{\alpha, t+1}\right) \Pi_{\alpha, t+1}^{I}-\phi_{\alpha, t+1} f_{\alpha, t+1}\right)
$$

Thus, the insider's bargaining surplus is

$$
\begin{aligned}
V_{\alpha, t}^{I}-V_{\alpha, t}^{\prime I}= & \left(w_{\alpha, t}(1-\tau)\right)^{\xi}+\delta\left(\left(1-\phi_{\alpha, t+1}\right) V_{\alpha, t+1}^{I}+\phi_{\alpha, t+1} V_{\alpha, t+1}^{S}\right) \\
& -\left(b_{\alpha, t}\right)^{\xi}-\delta\left(\left(1-\phi_{\alpha, t+1}\right) V_{\alpha, t+1}^{I}+\phi_{\alpha, t+1} V_{\alpha, t+1}^{S}\right) \\
= & \left(w_{\alpha, t}(1-\tau)\right)^{\xi}-\left(b_{\alpha, t}\right)^{\xi}
\end{aligned}
$$

and the firm's surplus is

$$
\begin{aligned}
\Pi_{\alpha, t}^{I}-\Pi_{\alpha, t}^{\prime I}= & \left(a_{\alpha}^{I}-w_{\alpha, t}+\sigma_{\alpha}\right)+\delta\left(\left(1-\phi_{\alpha, t+1}\right) \Pi_{\alpha, t+1}^{I}-\phi_{\alpha, t+1} f_{\alpha, t+1}\right)- \\
& \left(-f_{\alpha, t}+\delta\left(\left(1-\phi_{\alpha, t+1}\right) \Pi_{\alpha, t+1}^{I}-\phi_{\alpha, t+1} f_{\alpha, t+1}\right)\right) \\
= & a_{\alpha}^{I}-w_{\alpha, t}+\sigma_{\alpha}+f_{\alpha, t}
\end{aligned}
$$

The negotiated wage maximizes the Nash product $(\Lambda)$ :

$$
\Lambda=\left(\left(w_{\alpha, t}(1-\tau)\right)^{\xi}-\left(b_{\alpha, t}\right)^{\xi}\right)^{\gamma}\left(a_{\alpha}^{I}-w_{\alpha, t}+\sigma_{\alpha}+f_{\alpha, t}\right)^{1-\gamma},
$$

where $\gamma$ represents the bargaining strength of the insider relative to the firm. Thus, the following relationship holds:

$$
(1-\gamma)\left(\left[w_{\alpha, t}(1-\tau)\right]^{\xi}-b_{\alpha, t}^{\xi}\right)=\gamma \xi\left[w_{\alpha, t}(1-\tau)\right]^{\xi-1}\left(a_{\alpha}^{I}-w_{\alpha, t}+\sigma_{\alpha}+f_{\alpha, t}\right)(1-\tau) .
$$

In the labor market equilibrium, let firing costs be proportional to the wage, $f_{\alpha, t}=\rho w_{\alpha, t}$, and the unemployment benefit be proportional to the wage as well, $b_{\alpha, t}=\beta_{\alpha}(1-\tau) w_{\alpha, t}$, where $\beta_{\alpha}$ is the net replacement ratio. Then the negotiated wage is

$$
w_{\alpha}=\frac{\gamma \xi}{\left[(1-\gamma)\left(1-\beta_{\alpha}^{\xi}\right)+\gamma \xi(1-\rho)\right]}\left(a_{\alpha}^{I}+\sigma_{\alpha}\right)
$$

Since the wage is renegotiated in each period, the present value in period $t$ is independent of the present value in period $t+1$.

\subsection{Transitions Among Labor Market States}

The transitions among the labor market states are summarized in Figure (1). ${ }^{22}$ For analytical simplicity, we choose to describe these transitions in terms of a small number of transition variables.

The short-term unemployed $\left(U^{S}\right)$ are hired with probability $\eta^{S}$ and then become primary entrants $\left(N^{E 1}\right)$; with probability $\left(1-\eta^{S}\right)$ they remain unemployed and then join the longterm unemployed $\left(U^{L}\right)$, thereby losing productivity. The long-term unemployed are hired with probability $\eta^{L}$ and then become secondary entrants $\left(N^{E 2}\right)$; with probability $\left(1-\eta^{L}\right)$ they remain long-term unemployed.

\footnotetext{
${ }^{22}$ To simplify notation, we suppress the subscripts refering to ability $(\alpha)$ and time $(t)$ in this figure, e.g. short-term unemployment $\left(d_{u}=S\right)$ is written as $U^{S}$ rather than $U_{\alpha, t}^{S}$.
} 


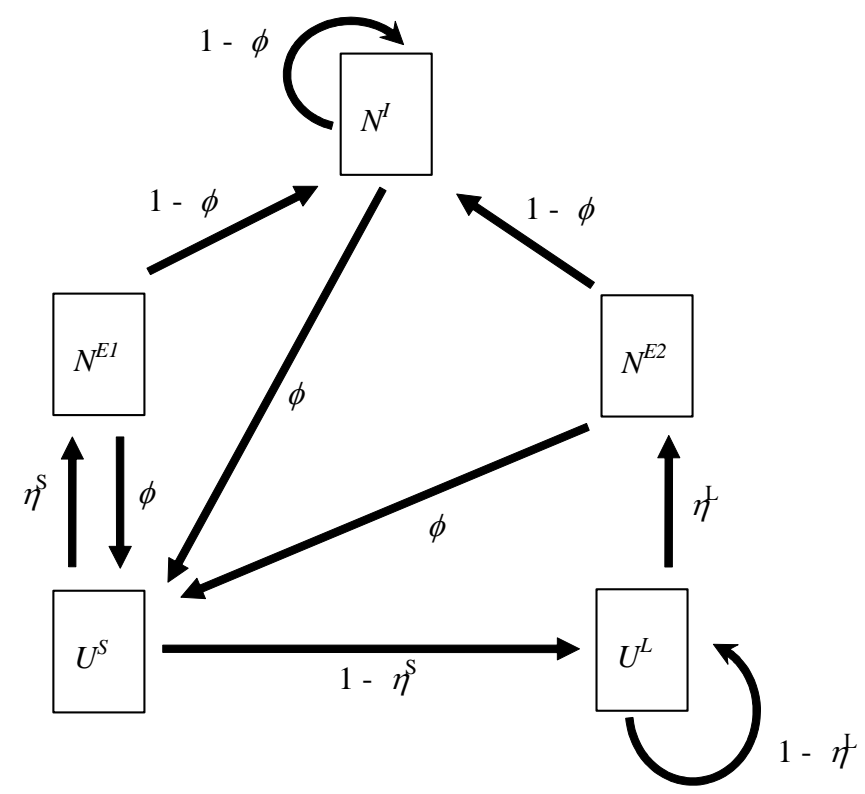

Figure 1: Transitions among Labor Market States

At the end of a period, the primary entrants turn into insiders $\left(N^{I}\right)$, and thereby gain productivity. As insiders, they lose their jobs with probability $\phi$ and then become primary entrants; with probability $(1-\phi)$ they are retrained. ${ }^{23}$ The same holds for the secondary entrants: they, too, turn into insiders, who have a $\phi$ chance of losing their jobs and a $(1-\phi)$ chance of retaining them. ${ }^{24}$

In short, human capital depreciates with the duration of unemployment and appreciates with the duration of employment.

Thus the labor market system for each ability group $a$ in period $t$ may be described as follows:

$$
S_{\alpha, t}=T_{\alpha, t} S_{\alpha, t-1}
$$

where $S_{t}$ is a vector of the labor market states:

$$
S_{\alpha, t}=\left(N_{\alpha, t}^{I}, N_{\alpha, t}^{E 1}, N_{\alpha, t}^{E 2}, U_{\alpha, t}^{S}, U_{\alpha, t}^{L}\right)^{\prime}
$$

and $T_{\alpha, t}$ is a Markov matrix of transition probabilities:

$$
T_{\alpha, t}=\begin{array}{ccccc}
\left(1-\phi_{\alpha, t}\right) & \left(1-\phi_{\alpha, t}\right) & \left(1-\phi_{\alpha, t}\right) & 0 & 0 \\
0 & 0 & 0 & \eta_{\alpha, t}^{S} & 0 \\
0 & 0 & 0 & 0 & \eta_{\alpha, t}^{L} \\
\phi_{\alpha, t} & \phi_{\alpha, t} & \phi_{\alpha, t} & 0 & 0 \\
0 & 0 & 0 & \left(1-\eta_{\alpha, t}^{S}\right) & \left(1-\eta_{\alpha, t}^{L}\right)
\end{array}
$$

We now proceed to derive the transition probabilities from microeconomic foundations.

\subsection{Hiring and Firing}

First consider the firing rate $\phi_{\alpha}$ for insiders. An insider is associated with the wage $w_{\alpha}$ and the firing cost $f_{\alpha}$. Let the time discount factor be $\delta$. Recalling that the insider's productivity

\footnotetext{
${ }^{23}$ Entrants turn into insiders at the end of a period. In case they are fired at the beginning of the next period these entrants have been insiders just for an instant. That is the reason why for expositional convenience in figure 1 we let entrants become insiders only if retained.

${ }^{24}$ Since all employed workers have the same productivity once they have been employed for a period (and thus, if they are retained, will become insiders in the next period), they all face the same firing probability $\phi$.
} 
is $a_{\alpha}^{I}$ and a wage subsidy for a worker with ability $\alpha$ is $\sigma_{\alpha}$, the expected present value of profit generated by an insider, after the random $\operatorname{cost} \varepsilon_{\alpha, t}$ at time $t$ is observed, is ${ }^{25}$

$$
\pi_{\alpha, t}^{I}=\left(a_{\alpha}^{I}-w_{\alpha}-\varepsilon_{\alpha, t}+\sigma_{\alpha}\right)+\sum_{i=t+1}^{\infty} \delta^{i}\left[\left(1-\phi_{\alpha}\right)^{i}\left(a_{\alpha}^{I}-w_{\alpha}+\sigma_{\alpha}\right)-\phi_{\alpha} f_{\alpha}\left(1-\phi_{\alpha}\right)^{i-1}\right]
$$

so that

$$
\pi_{\alpha, t}^{I}=\frac{a_{\alpha}^{I}-w_{\alpha}+\sigma_{\alpha}-\delta \phi_{\alpha} f_{\alpha}}{1-\delta\left(1-\phi_{\alpha}\right)}-\varepsilon_{\alpha, t}
$$

The expected incentive to retain the insider $\left(\nu_{\alpha}^{I}\right)$ is defined as the difference between the expected profit from retaining the insider $\left(\frac{a_{\alpha}^{I}-w_{\alpha}+\sigma_{\alpha}-\delta \phi_{\alpha} f_{\alpha}}{1-\delta\left(1-\phi_{\alpha}\right)}\right)$ and the expected profit from firing $\operatorname{him}\left(-f_{\alpha}\right)$, i.e. this insider retention incentive is

$$
\nu_{\alpha}^{I}=\frac{a_{\alpha}^{I}-w_{\alpha}+\sigma_{\alpha}-\delta \phi_{\alpha} f_{\alpha}}{1-\delta\left(1-\phi_{\alpha}\right)}+f_{\alpha}
$$

An insider is fired in period $t$ when the realized value of the random cost $\varepsilon_{\alpha, t}$ is greater than the insider employment incentive: ${ }^{26} \varepsilon_{\alpha, t}>\nu_{\alpha}^{I}$. Since the cumulative distribution of the operating cost is $\Gamma_{\alpha}\left(\varepsilon_{\alpha, t}\right)$, the insider's firing rate is

$$
\phi_{\alpha}=1-\Gamma_{\alpha}\left(\nu_{\alpha}^{I}\right)
$$

Next consider the hiring rate $\eta_{\alpha}^{S}$ for short-term unemployed workers. The expected present value of profit generated by a primary entrant (a worker who has been hired after being shortterm unemployed), after the random $\operatorname{cost} \varepsilon_{\alpha, t}$ at time $t$ is observed, is

$\pi_{\alpha, t}^{E 1}=\left(a_{\alpha}^{E 1}-w_{\alpha}-\varepsilon_{\alpha, t}-h_{\alpha}+\sigma_{\alpha}+\sigma_{\alpha}^{S}\right)+\sum_{i=t+1}^{\infty} \delta^{i}\left(\left(1-\phi_{\alpha}\right)^{i}\left(a_{\alpha}^{I}-w_{\alpha}+\sigma_{\alpha}\right)-\phi_{\alpha} f_{\alpha}\left(1-\phi_{\alpha}\right)^{i-1}\right)$

so that

$$
\pi_{\alpha, t}^{E 1}=a_{\alpha}^{E 1}-w_{\alpha}-\varepsilon_{\alpha, t}-h_{\alpha}+\sigma_{\alpha}+\sigma_{\alpha}^{S}+\frac{\delta\left(1-\phi_{\alpha}\right)\left(a_{\alpha}^{I}-w_{\alpha}+\sigma_{\alpha}\right)-\phi_{\alpha} f_{\alpha} \delta}{1-\delta\left(1-\phi_{\alpha}\right)},
$$

where $\sigma_{\alpha}^{S}$ is a hiring voucher for a short-term unemployed worker with ability $\alpha .^{27}$

The expected incentive to hire a short-term unemployed worker $\left(\nu_{\alpha}^{S}\right)$ is defined as the difference between the expected profit from employing the primary entrant and the expected profit from not doing so (i.e. zero). Thus the short-term unemployed hiring incentive is

$$
\nu_{\alpha}^{S}=a_{\alpha}^{E 1}-w_{\alpha}-h_{\alpha}+\sigma_{\alpha}+\sigma_{\alpha}^{S}+\frac{\delta\left(1-\phi_{\alpha}\right)\left(a_{\alpha}^{I}-w_{\alpha}+\sigma_{\alpha}\right)-\phi_{\alpha} f_{\alpha} \delta}{1-\delta\left(1-\phi_{\alpha}\right)}
$$

\footnotetext{
${ }^{25}$ In the first period, profit is $\left(a_{\alpha}^{I}-w_{\alpha}-\varepsilon_{\alpha, t}+\sigma_{\alpha}\right)$; in the second period, the insider is retained with probability $\left(1-\phi_{\alpha}\right)$ and then generates an expected profit of $a_{\alpha}^{I}-w_{\alpha}+\sigma_{\alpha}$, and the insider is fired with a probability of $\phi_{\alpha}$ and then generates a firing cost of $f_{\alpha}$; and so on.

${ }^{26}$ Equivalently, the insider is fired when the profit from retaining the insider is less than the firing cost: $\frac{a_{\alpha}^{I}-w_{\alpha}+\sigma_{\alpha}-\delta \phi_{\alpha} f_{\alpha}}{1-\delta\left(1-\phi_{\alpha}\right)}-\varepsilon_{\alpha, t}<f_{\alpha}$.

${ }^{27}$ Clearly, a wage subsidy raises current and expected future expected profits of all employees of the respective ability and thus, raises the hiring rates as well as lowers the firing rate. A hiring voucher, however, affects only the current period profit of the respectively subsidised entrant and thereby her respective hiring rate. For the influence of the subsidies in the linearized model see Appendix A.1.
} 
A primary entrant is hired in period $t$ when the realized value of the random $\operatorname{cost} \varepsilon_{\alpha, t}$ is less than the primary entrant hiring incentive: ${ }^{28} \varepsilon_{\alpha, t}<\nu_{\alpha}^{S}$. Thus the hiring rate for short-term unemployed is

$$
\eta_{\alpha}^{S}=\Gamma_{\alpha}\left(\nu_{\alpha}^{S}\right)
$$

Finally, consider the hiring rate $\eta_{\alpha}^{L}$ for the long-term unemployed. The expected present value of profit generated by a secondary entrant (a worker who has been hired after being long-term unemployed), after the random $\operatorname{cost} \varepsilon_{\alpha, t}$ at time $t$ is observed, is

$$
\pi_{\alpha, t}^{E 2}=a_{\alpha}^{E 2}-w_{\alpha}-\varepsilon_{\alpha, t}-h_{\alpha}+\sigma_{\alpha}+\sigma_{\alpha}^{L}+\frac{\delta\left(1-\phi_{\alpha}\right)\left(a_{\alpha}^{I}-w_{\alpha}+\sigma_{\alpha}\right)-\phi_{\alpha} f_{\alpha} \delta}{1-\delta\left(1-\phi_{\alpha}\right)}
$$

, where $\sigma_{\alpha}^{L}$ is a hiring voucher for a long-term unemployed worker with ability $\alpha$. The expected incentive to hire a long-term unemployed $\left(\nu_{\alpha}^{L}\right)$ is defined as the difference between the expected profit from employing the secondary entrant and the expected profit from not doing so (i.e. zero). Thus the long-term unemployed hiring incentive is

$$
\nu_{\alpha}^{L}=a_{\alpha}^{E 2}-w_{\alpha}-h_{\alpha}+\sigma_{\alpha}+\sigma_{\alpha}^{L}+\frac{\delta\left(1-\phi_{\alpha}\right)\left(a_{\alpha}^{I}-w_{\alpha}+\sigma_{\alpha}\right)-\phi_{\alpha} f_{\alpha} \delta}{1-\delta\left(1-\phi_{\alpha}\right)}
$$

A secondary entrant is hired in period $t$ when the realized value of the random $\operatorname{cost} \varepsilon_{\alpha, t}$ is less than the secondary entrant hiring incentive: ${ }^{29} \varepsilon_{\alpha, t}<\nu_{\alpha}^{L}$. Thus the hiring rate for long-term unemployed workers is

$$
\eta_{\alpha}^{L}=\Gamma_{\alpha}\left(\nu_{\alpha}^{L}\right)
$$

\subsection{Employment and Unemployment}

The change in employment in each ability group $\left(\Delta N_{\alpha, t}\right)$ is the difference between the outflow from the unemployment pool $\left(\eta_{\alpha, t}^{S} U_{\alpha, t-1}^{S}+\eta_{\alpha, t}^{L} U_{\alpha, t-1}^{L}\right)$ and the outflow from the employment pool $\left(\phi_{\alpha, t} N_{\alpha, t-1}\right)$ of that ability group: $\Delta N_{\alpha, t}=\eta_{\alpha, t}^{S} U_{\alpha, t-1}^{S}+\eta_{\alpha, t}^{L} U_{\alpha, t-1}^{L}-\phi_{\alpha, t} N_{\alpha, t-1}$. Assuming a constant labour force $L_{\alpha}$ in each ability class and defining the employment rate to be $n_{\alpha, t}=$ $N_{\alpha, t} / L_{\alpha, t}$, we obtain the following employment dynamics equation: ${ }^{30}$

$$
n_{\alpha, t}=\eta_{\alpha, t}^{S} u_{\alpha, t-1}^{S}+\eta_{\alpha, t}^{L} u_{\alpha, t-1}^{L}+\left(1-\phi_{\alpha, t}\right) n_{\alpha, t-1}
$$

The long-term unemployed comprise those workers who were either short- or long-term unemployed in the previous period and who have not been hired in the current period. Thus the long-run unemployment dynamics equation is

$$
u_{\alpha, t}^{L}=\left(1-\eta_{\alpha, t}^{S}\right) u_{\alpha, t-1}^{S}+\left(1-\eta_{\alpha, t}^{L}\right) u_{\alpha, t-1}^{L}
$$

The short-term unemployment rate is the difference between the aggregate unemployment rate and the long-term unemployment rate:

$$
u_{\alpha, t}^{S}=1-n_{\alpha, t}-u_{\alpha, t}^{L}
$$

\footnotetext{
${ }^{28}$ Equivalently, the primary entrant is hired when the profit from employing this worker is greater than than the hiring cost: $a_{\alpha}^{E 1}-w_{\alpha}-\varepsilon_{\alpha, t}+\sigma_{\alpha}+\sigma_{\alpha}^{S}+\frac{\delta\left(1-\phi_{\alpha}\right)\left(a_{\alpha}^{I}-w_{\alpha}+\sigma_{\alpha}\right)-\delta \phi_{\alpha} f_{\alpha}}{1-\delta\left(1-\phi_{\alpha}\right)}>h_{\alpha}$.

${ }^{29}$ Equivalently, the secondary entrant is hired when the profit from employing this worker is greater than than the hiring cost: $a_{\alpha}^{E 2}-w_{\alpha}-\varepsilon_{\alpha, t}+\sigma_{\alpha}+\sigma_{\alpha}^{L} \frac{\delta\left(1-\phi_{\alpha}\right)\left(a_{\alpha}^{E 2}-w_{\alpha}+\sigma_{\alpha}\right)-\delta \phi_{\alpha} f_{\alpha}}{1-\delta\left(1-\phi_{\alpha}\right)}>h_{\alpha}$

${ }^{30}$ Note that $\Delta n_{\alpha, t}=\eta_{\alpha, t}^{S}\left(1-n_{\alpha, t-1}^{S}\right)+\eta_{\alpha, t}^{L}\left(1-n_{\alpha, t-1}^{L}\right)-\phi_{\alpha, t} n_{\alpha, t-1}$.
} 


\subsection{The Labor Market Equilibrium}

The labor market equilibrium is the solution of the system comprising

- employment and unemployment dynamic equations (26), (27) and (28),

- the government budget constraint, equation (1),

- the firing and hiring rates, equations (18), (22), (25), and

- the wage equation (11).

We now proceed to calibrate the model above for German data and compare the effectiveness of alternatively targeted employment subsidies in terms of AWE. We will proceed as follows: first, the calibration, then an intuitive analysis of the effective policy design and then, the numerical results. In a further step, by relaxing the self-financing constraint, i.e. with a given positive net allocation of government expenditure to the policy, we compare the performance of our different subsidies in a marginal exercise beyond the approximately welfare efficient subsidy.

\section{Evaluation of Employment Subsidies}

\subsection{Calibration}

The period of analysis is one year. The interest rate $r$ is set at $4 \%$ per year, which corresponds to the average real interest rate in the OECD over the last four decades, and we set $\delta=\frac{1}{1+r}$. For simplicity, we begin by choosing a utility parameter $\xi=1$; later we also show results for $\xi=0.5 .^{31}$

Firing costs and hiring costs are set proportional to 60 percent $\left(f_{\alpha}=\rho w_{\alpha}\right.$ with $\left.\rho=0.6\right)$ and 10 percent $\left(h_{\alpha}=\mu w_{\alpha}\right.$ with $\left.\mu=0.1\right)$ of the the labor costs respectively (Chen and Funke (2003)). The net replacement rates $\beta_{\alpha}$ are set to 78.25 percent for low-ability, 68.25 percent for medium-ability, and 64.67 percent for high-ability workers (OECD (2006)). ${ }^{32}$ The tax-rate $\tau$ that balances the government's budget in the absence of subsidies amounts to 0.069 .

Keane and Wolpin (1997) estimated rates of skill depreciation during unemployment: white collar workers lose about 30 percent of their skills after being unemployed for one year, whereas the number is about 10 percent for blue collar workers. ${ }^{33}$ In Ljungqvist and Sargent (1998) the rate of depreciation of skills during unemployment is twice the rate of accumulation. ${ }^{34}$ In line with these studies we assume an insider productivity advantage is 10 percent and a skill depreciation of 20 percent of the respective productivity due to long-term unemployment.

Table $(1)^{35}$ shows the percentage values for Germany for the three ability classes of the relevant variables of the employment dynamics equations. The percentage share of the labour force $l_{\alpha}$ for each ability class for Germany (2002) is taken from OECD (2005a), the respective aggregate unemployment rates for Germany (2002) $u_{\alpha, 0}$ from OECD (2005b, 2005c). The actual hiring rates for 1996 of each ability and duration group $\eta_{\alpha, 0}^{S}$ and $\eta_{\alpha, 0}^{L}$ are taken from Wilke's (2005) Kaplan-Meier functions for Germany. According to OECD (2005b, 2005d) the average share of long-term unemployment $\left(u_{\alpha, 0}^{L} / u_{\alpha, 0}\right)$ is around 50 percent and similar across all ability

\footnotetext{
${ }^{31}$ For the latter, we have decreasing marginal utility of consumption. Thus, in the aggregated welfare function a bigger weight is given to an improvement of low ability workers' income (being closer to Rawlsian welfare).

${ }^{32}$ See Appendix A.2.1 for a description of the calculation of these rates.

${ }^{33}$ See Keane and Wolpin (1997), p. 500.

${ }^{34}$ See Ljungqvist and Sargent (1998), p. 527.

${ }^{35}$ Note that variables with subscript "0" denote the value at the "old" steady state, i.e. before any policy exercise, while variables with subscript "new" denote the new steady state after the policy exercise shows its full effects.
} 


\begin{tabular}{|l|c|c|c|c|}
\hline & low-ability & medium-ability & high-ability & aggregate \\
\hline$l_{\alpha}$ & 16.6 & 59.4 & 24 & 100 \\
\hline$u_{\alpha, 0}$ & 18 & 10.2 & 5.2 & 10.3 \\
\hline$u_{\alpha, 0}^{S}$ & 7.7 & 5.1 & 2.8 & 5 \\
\hline$u_{\alpha, 0}^{L}$ & 10.3 & 5 & 2.4 & 5.3 \\
\hline$u_{\alpha, 0}^{L} / u_{\alpha, 0}$ & 57 & 49 & 46 & 50 \\
\hline$\eta_{\alpha, 0}^{S}$ & 49 & 59 & 55 & 56.4 \\
\hline$\eta_{\alpha, 0}^{L}$ & 38 & 42 & 51 & 43.5 \\
\hline$\phi_{\alpha, 0}$ & 9.4 & 5.7 & 2.9 & 5.6 \\
\hline
\end{tabular}

Table 1: Steady state values of the labor share, unemployment, hiring and firing rates for each skill class and in aggregate in percentage for Germany (before a policy exercise).

classes. $^{36}$ The firing rates $\phi_{\alpha, 0}$ are assigned the values necessary for the model to reproduce the unemployment rates of the respective ability classes $^{37}$. We interpret these numbers as steady state values.

We linearize the model around the old steady state (see Appendix A.1) and calculate the long-run effects of the policy exercises (new steady state) as permanent deviations from the old steady state. Thus, we have to choose the first derivative of the cumulative density functions in our model $\left(\Gamma_{\alpha, 0}^{\prime}\right)$, which determines the hiring and firing elasticities. For this purpose, we use empirical estimates, as summarized in Orszag and Snower (1999, p. 208). The first derivative of the cumulative function for the hiring rate $\left({ }_{\eta} \Gamma_{\alpha, 0}^{\prime}\right)^{38}$ (denoted with subscript $\left.{ }_{\eta}\right)$ is set in such a way that the hiring elasticity with respect to a hiring voucher is equal to $0.5 .^{39}$ Also in line with the aforementioned empirical literature, we set the first derivative of the cumulative function $\left({ }_{\phi} \Gamma_{\alpha, 0}^{\prime}\right)^{40}$ for the firing rate (denoted with subscript ${ }_{\phi}$ ) in such a way that a one-period reduction of the wage has an elasticity of 0.125 .

To double check that we have chosen appropriate hiring and firing elasticities, we compare the endogenous reactions of our model to the empirical labor demand literature. A permanent 10 percent wage cut (ceteris paribus) for low-ability workers generates for example an increase in the employment rate of 8.7 percent in the long-run, which yields an long-term labor demand elasticity of $-0.87 .{ }^{41}$

Empirical labor demand elasticities for Germany are generally estimated in a range from -0.3 to $-0.9^{42}$. Sinn et al. (2006, p. 10) point out that these estimation results rather reflect

\footnotetext{
${ }^{36}$ See also SVR (2005). In our calibration the share of long-term unemployed is somewhat above $50 \%$ for the low-ability and slightly below $50 \%$ for the medium- and high-ability, which seems plausible.

${ }^{37}$ The firing rate of $9 \%$ for low-ability employees is pretty close to what can be found in the literature (e.g. Brussig and Erlinghagen (2005), Fitzenberger et al. (2003) and Wilke (2005)). The firing rate for high-ability is somewhat lower than in reality since many high-ability workers rotate back into work quickly. This phenomenon cannot be captured by our model since it is calibrated on a yearly basis and workers stay unemployment for at least a year. However, this property does not affect the model dynamics for the performed exercises.

${ }^{38}$ See Appendix A.1.2.

${ }^{39}$ Reaction of the hiring rate to a hiring voucher for short-term unemployed, which is permanently paid during the first year of the employment spell $\left(\chi_{\alpha}=\frac{\partial \eta_{\alpha}^{S}}{\eta_{\alpha}^{S}} / \frac{\partial \sigma_{\alpha}^{S}}{w_{\alpha}}\right)$. For simplicity, we choose the same ${ }_{\eta} \Gamma_{0, \alpha}^{\prime}$ for short-term and long-term unemployed in each ability group.

${ }^{40}$ See Appendix A.1.1.

${ }^{41}$ Note that the endogenous labor demand elasticity in our model varies with the size of the wage movement. The bigger the change in the wage, the smaller is the labor demand elasticity (in absolute terms).

${ }^{42}$ See Riphan et al. (1999).
} 
short-term than long-term elasticities, refer to studies where considerable higher estimates have been found for the low wage sector and consider an elasticity of -1 as realistic. Thus, we see ourselves well in line with the empirical labor demand literature for Germany. For a detailed description of the approximations for different abilities' labor costs and wages see Appendix A.2.2.

Starting from this steady state we will perform policy exercises and compare the resulting new steady states. ${ }^{43}$

\subsection{Effective Policy Design}

We compare the effectiveness of differently targeted employment subsidies under the notion of AWE. As noted, the following criteria have to hold: (i) the subsidies improve aggregate employment and welfare (defined as the sum of the utility of the workforce), (ii) they do not increase earnings inequality (measured in terms of the Gini coefficient ${ }^{44}$ ), and (iii) they are selffinancing (i.e., they do not require a net allocation of government expenditures to the subsidy in the new steady state, $G=0$.)

It is of course possible that employment subsidies be self-financing. An employment increase (generated by the subsidy) broadens the tax base and thereby, raises the government's revenue, and lower unemployment implies less expenditures on benefit payments. Thus, to be selffinancing the subsidies must be financed by the additional tax revenue and the reduction in benefit payments:

$$
\sum_{\alpha} \sum_{d_{u}} \sigma_{\alpha}^{d_{u}} u_{\alpha}^{d_{u}} l_{\alpha} \eta_{\alpha}^{d_{u}}+\sum_{\alpha} \sigma_{\alpha} l_{\alpha} n_{\alpha}=\left(\Delta \sum_{\alpha} n_{\alpha} l_{\alpha} w_{\alpha} \tau-\Delta \sum_{\alpha} \sum_{d_{u}} u_{\alpha}^{d_{u}} l_{\alpha} b_{\alpha}\right)
$$

, where $\Delta$ denotes the difference between the value at the new steady state after the policy exercise shows its full effects and the value at the "old" steady state, i.e. before any policy exercise.

As our numerical results will show, the self-financing constraint is reached before the other constraints associated with approximate welfare efficiency are reached. It turns out that some policies under consideration are not AWE, as they are not self-financing at all.

Thus, before discussing the simulation results, in the following we discriminate different targeting schemes by their potential of being self-financing. Thereby, we identify the main effects that influence the existence and the size of a self-financing area.

\subsubsection{Wage Subsidies versus Hiring vouchers}

Let us start with comparing the two most general types of subsidies:

- a wage subsidy $\sigma_{\alpha}$ paid to the firm for each employed worker of a specific ability class $^{45}$,

- 1-period hiring voucher $\sigma_{\alpha, t}^{d_{u}}$ paid to the firm for hiring a worker of a specific target group (duration and ability).

Our quantitative analysis will show that self-financing areas are more likely to exist and, if they exist, will be larger for hiring vouchers than for wage subsidies. Intuitively, this arises for the following reasons: ${ }^{46}$

\footnotetext{
${ }^{43}$ See Appendix A.1.

${ }^{44}$ Note that the Gini coefficient generated by our model is lower than in reality, as our model does not generate income differentials within ability groups and it does not take non-wage related inequalities into account (e.g., due to the wealth distribution).

${ }^{45}$ Normally, wage-subsidies are targeted at the low-ability workers, i.e. low-wage subsidies, $\alpha=l$.

${ }^{46}$ The following effects are strongly interrelated and reciprocally reinforcing. Thus, we will not try to disentangle them in our numerical excercise.
} 
Deadweight Effect First of all, the deadweight ${ }^{47}$ (defined as the rate of subsidy payments which are paid to workers who would have been employed in absence of the subsidy) is much larger for wage subsidies than for hiring vouchers. Naturally, the latter also implies some deadweight, vouchers to those unemployed workers who would have been hired also in absence of the subsidy, whereby the deadweight of the former additionally includes subsidies to all employed workers who would have been retained in absence of the subsidy. ${ }^{48}$

Wage Effect The wage-effect plays an important role for wage-subsidies. ${ }^{49}$ It is defined as the proportion of the subsidy, which does not increase the firm's surplus, as it is neutralised by wage increases and thus not used for employment creation. Since wages are determined by insiders in our model and wage subsidies are paid for all employed workers of a specific ability, also for insiders, the latter will try to reap part of the subsidy, as they are part of the employers' surplus. Thus, a share of the subsidy goes directly to the workers and the increase in firm's employment incentives for workers of the respective ability class are weakened.

Summary These two effects make a strong case that hiring vouchers are more likely to be self-financing and thus, AWE than wage subsidies.

\subsubsection{Duration versus Ability}

As the deadweight effect and the wage effect seem to favor hiring vouchers, we now proceed to analyze whether they should be targeted at specific duration or ability groups. Besides the deadweight effect, the existence and size of a self-financing subsidy very much dependent on the replacement rate and transition effect:

Deadweight Effect The greater is the hiring rate in the initial steady state, the larger will be the deadweight implied by a hiring voucher. As can be seen in table (1), empirically, hiring rates in general increase with productivity. Thus, hiring vouchers should be targeted at workers with the lowest productivity, namely low-ability workers as well as long-term unemployed workers.

Replacement Rate Effect As shown above, the lower the income and ability, the higher is the replacement rate. Thus, increased employment in the group with the lowest income will generate the largest reduction in government expenditures (in terms of the respective wage). ${ }^{50}$ Hence, the government can grant a higher voucher relative to the respective wage. Thereby, ceteris paribus, the higher is the replacement rate, the more likely is the hiring voucher to be self-financing. The replacement effect clearly favors hiring vouchers for low-ability workers. ${ }^{51}$

Transition Effect If a hiring vouchers brings a worker back to work, her human capital appreciates in our model. In our model the human capital appreciation implies that the formerly short- and long-term unemployed have the same productivity as insiders after one period. As a consequence, their low hiring probability $\left(\eta_{\alpha, t}^{d_{u}}\right)$ is exchanged for a considerably higher retention probability $\left(1-\phi_{\alpha, t}\right)$. This effect is strongest for long-term unemployed since they have been

\footnotetext{
${ }^{47}$ The subsidy deadweight effect affects the left hand-side of equation (29)).

${ }^{48}$ For example, $82 \%$ of the low-skilled workers in Germany are already employed in absence of a low-wage subsidy, while this groups contains $16.6 \%$ of all workers. Thus, $13.6 \%$ of the workforce would receive a low wage subsidy, although these people would be employed without a subsidy. For hiring vouchers deadweight subsidy payments cover only about $5 \%$ of the workforce.

${ }^{49}$ See right hand-side of the self-financing constraint $\left.(29)\right)$.

${ }^{50}$ This affects the right hand-side of equation (29).

${ }^{51}$ As insider bargain for the wage, long-term unemployed workers receive the wage of the respective ability class. Naturally, low-ability workers have the lowest wage.
} 
most affected by human capital loss. Thus, subsidies enabling workers to move to a higher productivity class have a bigger long-run effect on the government budget. Clearly, this effect favors hiring vouchers for long-term unemployed workers.

Summary While the last effect is in favor of targeting long-term unemployed, the second delivers an argument for targeting low-ability unemployed and the first is ambiguous. The intuition is straightforward, hiring vouchers are more effective, the least skilled/productive the targeted workers are, i.e. the longer they have been unemployed and the lower their ability is. Which low-productivity class of workers is the most effective target group for hiring vouchers for Germany can only determined by our following numerical simulation.

\subsection{Numerical Results}

We simulate our above model for Germany, and compare the effectiveness of the following employment subsidy policies:

(i) A low-wage subsidy $\left(\sigma_{l}\right)$ which is paid (each period) for each low-wage/ability employee. It will reduce the firing rate, by making employees more profitable for the firm. Thus, it raises the insider retention incentive, whereby the firm retains more workers with high operating costs (low productivity).(see equations (18), (17))

At the same time the hiring rate will increase since the subsidy provides the incentive to hire more low productivity workers, which would not have been hired otherwise. (see equations (21), (22) and (24), (25))

(ii) A hiring voucher targeted at low-ability workers $\left(\sigma_{l}^{d_{u}}\right)$, which is paid for hiring unemployed, low-ability workers. Following the same rationale as above, the firm will hire more workers than without a voucher. In contrast to the first policy, the firing rate will not be affected since the voucher is only paid for new hires and not for the entire employment stock.(see equations (21), (22) and (24), (25))

(iii) A hiring voucher targeted at long-term unemployed workers $\left(\sigma_{\alpha}^{L}\right)$, which is paid if a long-term unemployed worker is hired. (see equations (24), (25))

(iv) A hiring voucher targeted at the low-ability, long-term unemployed workers $\left(\sigma_{l}^{L}\right.$; see equations (24), (25))

In a first step, we identify the policies which are AWE and compare their effectiveness. But as noted the self-financing criterion is the limiting factor and some policies do not satisfy this constraint. While it may not be approximately welfare efficient, it may nonetheless be desirable for policy makers to prioritize the employment and welfare creation - without increasing inequality - compared to other government tasks. Then the government allocates a positive net expenditure to these subsidies, $G>0$. Thus, in a second step we examine the performance of the differently targeted employment subsidies (i)-(iv) with respect to the remaining two criteria, given an positive net expenditure allocation to these subsidies beyond their approximate welfare efficiency.

\subsubsection{Approximately Welfare Efficient Targeting}

Our simulation reveals that a low-wage subsidy is not an AWE policy for Germany. While a low-wage subsidy creates more employment and reduces inequity, it is not self-financing. This result is driven by the deadweight effect and the wage effect, as described above. Thus, low wage subsidies can only be implemented if the government is willing to provide extra resources permanently. We will analyze their performance in this respect below.

Furthermore, our results show that hiring vouchers for Germany can be self-financing and thereby AWE, depending on the target group. 
To determine the most effective employment subsidy, we examine the approximately welfare efficiency of hiring vouchers targeted at the low-productivity groups, namely at long-term unemployed as well as at the low-ability unemployed, and compare their employment, welfare and equity effects.

For both groups there are two possible options for hiring vouchers $(\mathrm{HV})$ :

Option 1: a same lump sum voucher is paid for hiring a long-term unemployed worker (low- ability worker) irrespectively of his ability class (unemployment duration),

Option 2: a different voucher is paid for hiring a long-term unemployed worker (low- ability worker) depending on his ability class (unemployment duration).

While option 1 implies a voucher which is self-financing across ability classes (unemployment duration), option 2 (unemployment duration) is determined to be self-financing within each ability class (unemployment duration), thereby, preventing cross-subsidization across ability classes (unemployment duration).

Targeting Long-Term Unemployed: Vouchers targeted at long-term unemployed (LTU) workers are AWE for Germany. Table (2) compares the effectiveness of the two design options by describing their unemployment, welfare ${ }^{52}$ and equity implications, the latter given by the Gini coefficient.

If a same lump sum hiring voucher is paid for all long-term unemployed compared to an ability specific payment, the self-financing restriction is hit much earlier. While only $947 €$ per worker are AWE in the former case, up to $4390 €(2503 €)$ can be paid for low-ability (medium-ability) workers in the latter. The intuition is straightforward: option 2 fully exploits the larger self-financing areas for long-term unemployed workers in the low-ability and mediumability class, thereby, it prevents costly cross-subsidization. The self-financing area and thereby, the self-financing, approximately welfare efficient subsidy decreases with productivity due to a smaller deadweight effect and the bigger replacement rate effect.

By comparing the results of these two exercises, we can clearly infer that hiring vouchers of different magnitudes for each ability group deliver a superior effectiveness. They perform better in terms of unemployment reduction, welfare improvement and inequality reduction. According to our calibration the long-term unemployment among low-ability workers can be e.g. reduced by 9 percent "for free," ${ }^{53}$ i.e. from roughly 10 percent to 9 percent of all low-ability workers.

\begin{tabular}{|l|l|c|c|}
\hline & & HV for LTU Option 1 & HV for LTU Option 2 \\
\hline $\mathbf{1}$ & Subsidy & $\mathbf{9 4 7}$ & $\mathbf{4 3 9 0 / 2 5 0 3 / 0}$ \\
\hline $\mathbf{2}$ & Subsidy in \% of respective wage & $\mathbf{3 . 7 / 3 . 1 / 2 . 2}$ & $\mathbf{1 6 . 9 / 8 . 4 / 0}$ \\
\hline $\mathbf{3}$ & $\%$ Change of Low-Ability Long-Term Unemployment & -2.1 & -8.9 \\
\hline $\mathbf{4}$ & $\%$ Change of Low-Ability Unemployment & -0.8 & -4.4 \\
\hline $\mathbf{5}$ & \%Change of Long-Term Unemployment & $-\mathbf{2 . 0}$ & -5.9 \\
\hline $\mathbf{6}$ & $\%$ Change of Overall Unemployment & -0.9 & $-\mathbf{2 . 8}$ \\
\hline $\mathbf{7}$ & Change of Welfare & $\mathbf{+}$ & $\mathbf{+}$ \\
\hline $\mathbf{8}$ & Gini coefficient (old steady state 11.47) & $\mathbf{1 1 . 4 5}$ & $\mathbf{1 1 . 4 1}$ \\
\hline
\end{tabular}

Table 2: Approximately welfare efficient hiring vouchers (HV) for long-term unemployed (LTU) workers in design options 1 and 2 and the resulting unemployment, welfare and equity implications. [Opiton 2 vouchers are differentiated in those for low-, medium- and high-ability]

\footnotetext{
${ }^{52}$ The welfare of the workforce is calculated as the sum of the utility of the workers over the various labor market states. See Appendix (A.3). A "+" for welfare changes indicates an increase in welfare. The crosspolicy ranking of changes in welfare corresponds to the ranking of changes in overall unemployment. The utility parameter $\xi$ does not affect the cross-policy rankings.

${ }^{53}$ Without any bet allocation of government resources to this policy in the long-run.
} 


\begin{tabular}{|l|l|c|}
\hline & & HV for LAU Option 2 \\
\hline $\mathbf{1}$ & Subsidy & $\mathbf{4 3 9 0} / \mathbf{0}$ \\
\hline $\mathbf{2}$ & Subsidy in \% of respective wage & $\mathbf{1 6 . 9}$ \\
\hline $\mathbf{3}$ & $\%$ Change of Low-Ability Long-Term Unemployment & -8.9 \\
\hline $\mathbf{4}$ & $\%$ Change of Low-Ability Unemployment & -4.4 \\
\hline $\mathbf{5}$ & \% Change of Long-Term Unemployment & $-\mathbf{2 . 9}$ \\
\hline $\mathbf{6}$ & $\%$ Change of Overall Unemployment & -1.4 \\
\hline $\mathbf{7}$ & Change of Welfare & + \\
\hline 8 & Gini coefficient (old steady state 11.47) & $\mathbf{1 1 . 4 5}$ \\
\hline
\end{tabular}

Table 3: Approximately welfare efficient hiring vouchers (HV) for low-ability unemployed (LAU) workers in design option 2 and the resulting unemployment, welfare and equity implications. [Vouchers are differentiated in those for long-term and short-term unemployed]

Targeting Low-Ability Unemployed: If a lump sum hiring voucher is targeted at all lowability unemployed (LAU) (option 1), there is no self-financing area at all.

But as shown in table (3) differentiating the vouchers for short-term and long-term unemployed workers reveals an approximately welfare efficient hiring voucher for low-ability workers (4390 €), which though is present only for long-term unemployed workers. The reason is that short-term unemployed workers have a higher productivity than the long-term unemployed, thereby a higher hiring rate, which implies a higher deadweight effect and a smaller transition effect. Both impede a self-financing are for these workers.

Clearly, AWE hiring vouchers for long-term unemployed workers - in their more effective option 2 targeting - nest the AWE hiring vouchers for low-ability workers - in option 2 targeting -, which is a special hiring voucher for low-ability, long-term unemployed workers.

Thereby, it is worth emphasizing that thus, for Germany targeting vouchers at long-term unemployed workers (targeted at the low- and medium-ability workers) is more effective than targeting low-ability workers.

Overall, it has to be mentioned that the size of the approximately welfare efficient subsidy depends crucially on the hiring elasticities. We claim that they can be influenced substantially by policy makers. Designing a successful subsidy system should include complementary measures $^{54}$, such as tightening unemployment benefits or firing costs, improving job placement or increasing the pressure to accept job offers, to ensure the aforementioned simulated or even better long run effects.

Employment-Equity Trade-Off: Interestingly, the self-financing hiring voucher reduces the economy's unemployment and inequity at the same time. Thus, a hiring voucher does not face an employment-equity trade-off. It is possible to improve at both ends. This is all the more interesting since other simulated policy measures, such as a reduction of the replacement rate for the low-ability workers (which are the most unemployment prone) would buy more employment at the cost of a higher Gini coefficient; thus facing an employment-equity trade-off.

Displacement Effects: The critical reader may wonder if our results differ significantly if we consider displacement (and not only deadweight) effects in our model. The simplest way to incorporate them are short-run decreasing returns to labor under fixed capital. When labor input is increased by factor $x$ (with $x>1$ ), under a Cobb-Douglas function $Y=A N^{1-\alpha} \bar{K}^{\alpha}$ we would obtain the following marginal product: $\partial Y / \partial N=x^{-\alpha}(1-\alpha) A N_{0}^{-\alpha} \bar{K}^{\alpha}$. If the labor input increases by 1 percentage point (which corresponds roughly to a 1 percentage point

\footnotetext{
${ }^{54}$ See Coe and Snower (1997) and Orszag and Snower (1998).
} 
reduction of unemployment), the marginal product would decrease by 0.3 percentage points (assuming a capital share of 33 percent for Germany, see Statistisches Bundesamt (2006)). This would reduce the wage claim of the insiders, but nevertheless reduce the profit of the firm somewhat. The AWE hiring vouchers for low-ability, long-term unemployed workers is reduced from 17 to 15 percent by this exercise. Thus, our results are not affected qualitatively and only slightly quantitatively. Furthermore, we consider displacement to be rather a short-run phenomenon because capital adjusts in the long-run. ${ }^{55}$

\subsubsection{Relaxing the Self-Financing Constraint}

Approximately welfare efficient policies can contribute to reduce the unemployment, but according to our calibration they would surely not be sufficient to bring Germany back to full employment. Thus, we analyze the performance of differently targeted subsidies, once we go beyond the approximately welfare efficient subsidy. ${ }^{56}$ We define a policy measure to outperform the other policies if it delivers the biggest marginal effects in terms of the two remaining policy objectives for a given additional amount of government spending.

Specifically, we assume that in the long-run the government is willing to allocate a net expenditure of $€ 50$ ( $G=50$, per year and per person of the workforce $\left.{ }^{57}\right)$ for active labor market policies. ${ }^{58}$ Note that the gross amount of money which is additionally allocated to the policies is larger since part of the additional expenses are financed by additional revenue, generated by resulting higher employment levels. These expenditures are allocated to the targeted groups by increasing the subsidy (in equal Euro steps for all targeted groups) until the (new steady state's) budget constraint is reached.

\begin{tabular}{|c|c|c|c|c|}
\hline & & HN for LTU(Cation2) & HN for LAU (qation2) & Lav-Wage Subsidy \\
\hline 1 & Total Subsidy(\%of respectivenege) & $51.7 / 385 / 20.5$ & $64.6 / 47.7$ & 15 \\
\hline 2 & Additional Subsidy & 9033 & 12363 & 403 \\
\hline 3 & \%Marginal Reduction of LowAbbility Unemployment & -7.8 & -18.7 & -15 \\
\hline 4 & \%Marginal Reduction of Long-Term Unemploymert & -15.1 & -114 & -0.8 \\
\hline 5 & \%Narignal Reduction of Oerall Unemployment & -7.1 & -5.3 & -0.4 \\
\hline 6 & \%Total Reduction of Low-Ability Unemployment & -118 & -223 & -15 \\
\hline 7 & \%Total Reduction of Long-Term Unemployment & -20.1 & -14 & -0.8 \\
\hline 8 & \%Total Reduction of Overall Unemployment & -9.7 & -66 & -0.4 \\
\hline & Gini coefficient & 11.29 & 1138 & 1132 \\
\hline
\end{tabular}

Table 4: Unemployment and inequality effects of hiring vouchers (HV) for long-term unemployed (LTU) and low-ability unemployed (LAU) workers - in design option 2 - and low-wage subsidies beyond their approximate welfare efficiency, i.e. with a net allocation of government expenditure of $50 €$ per worker. [Vouchers for LTU are differentiated in those for low-, medium- and high-ability, vouchers for LAU in those for long-term and short-term unemployed.]

\footnotetext{
${ }^{55}$ Although our quantitative analysis above omits displacement effects, we consider our calibration to be rather conservative (with respect to the size of the approximately efficient subsidy). While we used a tax rate (6.9 percent) to balance the budget (financing unemployment related expenses), in reality other taxe revenue would also increase with the employment rate. This would raise the self-financing, and thereby approximately efficient subsidy and thus lead to a higher effectiveness (in terms of employment, welfare and inequality).

${ }^{56}$ However, we do not calculate a welfare measure for this exercise since the government either has to cut other spending positions (which may reduce the agents' utility) or create government debt (which has to be paid by future taxes).

${ }^{57}$ The number has to be interpreted as a real value.

${ }^{58}$ For Germany with a workforce of roughly 40 million, this would amount to about 2 billion Euro. This amount, $G$ might reflect, as noted, a budget deficit or savings in other areas.
} 
Table (4) presents the implications for the government's objectives unemployment and inequality of this marginal exercise beyond the AWE subsidy, comparing hiring vouchers for long-term unemployed (LTU) and for low-ability (LAU) workers and low-wage subsidies. The marginal unemployment reduction refers to the approximately welfare efficient steady state, i.e. the steady state with the respective AWE subsidy, whereas the total reduction is calculated with respect to the old steady state. ${ }^{59}$

Employment Effects: For the same two reasons as mentioned above, low wage subsidies perform worse in reducing unemployment: First of all, the deadweight effect is quite substantial.

While the hiring voucher targeted at the long-term unemployed is paid to roughly 2.2 percent of the overall working population, it is almost 13.6 percent for low-wage subsidies; indicating a much larger deadweight for the latter. Furthermore, as noted, there is a considerable wage effect: the subsidy is not used entirely to improve the employment incentive of the firm (and thus increase employment). Part of it goes directly to the employed workers since it affects the bargaining.

For these two reasons low-wage subsidies underperform in relative terms: 99.7 percent of the recipients get the subsidy, although they would also have been employed in the absence of a subsidy. The ratio is quite big for hiring vouchers targeted at long-term unemployed (68.5 percent) as well; nevertheless considerably smaller. Thus, in contrast to low-wage subsidies, hiring vouchers (targeted at long-term unemployed, see column one of table (4), or the lowability unemployed, see column two) come along with a substantial size per subsidized worker (for a given net government allocation) and deliver a bigger employment effect. ${ }^{60}$

Again, also in this marginal exercise for Germany, the hiring voucher targeted at low-ability unemployed workers is outperformed by the one targeted at long-term unemployed workers: in terms of the marginal reduction as well as the overall reduction of total unemployment. Besides the transition effect, another reason can be found in the employment dynamics equation (26). In our model it is much easier to obtain small employment effects for a given ability group compared to a large effect, i.e. labor demand elasticities are bigger, the smaller the marginal expenses are. ${ }^{61}$ The hiring voucher for low-ability, long-term unemployed is larger if the given net expenditure is exclusively targeted at low-ability workers (64.6 percent, see column two of table (1)) compared to targeting it exclusively at long-term unemployed (51.7 percent, see column one of table (4)). As a consequence, the labor demand elasticity (in absolute values) in the former case is smaller than in the latter.

Thus, it is a better strategy to focus a given net expenditure on long-term unemployed workers in different ability classes, compared to restricting the hiring voucher only to the lowability unemployed. Our simulation indicates that a policy which is targeted at long-term unemployed and which has the aforementioned size could cut long-term unemployment by 20 percent and overall unemployment by roughly 10 percent.

Equity Effects: While our model shows that hiring vouchers are a much better instrument to reduce unemployment than low wage subsidies, the answer is more ambiguous with respect to equity. The Gini coefficient improves for wage subsidies and hiring vouchers; even somewhat more for hiring vouchers. But there are two countervailing effects at work:

\footnotetext{
${ }^{59}$ Naturally, as low-wage subsidies are not approximately efficient, the marginal reduction is equal to the overall.

${ }^{60} \mathrm{All}$ calculations are based on the new steady state. To provide a fair comparison, the approximately welfare efficient part of the hiring subsidies is not taken into account.

${ }^{61}$ This is most easy to see under homogenous labor where the long-run employment is equal to $n=\frac{\eta}{\eta+\phi}$ (see Snower and Merkl (2006)). The marginal employment effect of an increasing hiring rate obviously is posive, but decreasing $\left(\frac{\partial n}{\partial \eta}>0, \frac{\partial^{2} n}{\partial \eta^{2}}<0\right)$.
} 
The low-wage subsidies are targeted at two groups which are at the lower end of the income scale (low-ability unemployed and employed) and improve their income via the bargaining mechanism. As the low-ability insiders bid for a higher wage, the income of the low-ability workers increases (while their employment increases somewhat too), namely wages and indirectly benefits.

While the hiring vouchers are not as clearly targeted at the "poorest" groups (also hiring of high-ability long-term unemployed is subsidized) and do not have a direct wage effect, their incentive effect is much bigger. They improve equality by bringing the long-term unemployed back to work: In contrast to that low-wage subsidies do so by putting money in the pockets of low-income people (without generating much additional employment).

Hiring vouchers for long-term unemployed workers reduce inequality by more compared to hiring vouchers for low-ability workers, as they have bigger employment effects.

Low wage subsidies can be considered to be an instrument which is in between unemployment benefits and hiring vouchers in terms of their employment-equity trade-off. While higher unemployment benefits for the low-ability workers can improve equity (giving more money to the poorest in our model: the low-ability unemployed), they destroy the firm's employment incentives (via wage bargaining, as the workers' fallback position increases) and thus increase unemployment. For a given budget constraint low-wage subsidies improve employment incentives only slightly but increase the income of low-income workers. And hiring vouchers increase employment incentives substantially, thus reducing inequality by bringing people back into work; thus yielding less unemployment and more equity at the same time.

\section{Concluding Thoughts}

This paper has proposed a new criterion for the evaluation of employment subsidies: approximately welfare efficient (AWE) policies are self-financing and improve employment/welfare, without increasing earnings inequality. Policies satifying this criterion can be expected to be particularly attractive to policy makers. We have compared various popular employment subsidies on this basis. Needless to say, approximate welfare efficiency is a highly conservative criterion; policy makers may well wish to implement measures that are not AWE, but in that case they need to move along an equity-efficiency tradeoff (viz., they need to sacrifice either employment/welfare or earnings equality ${ }^{62}$ ).

Our analysis indicates that the employment policies under consideration exhibit diminishing returns, in that equal incremental increases in each employment subsidy lead to progressively smaller increases in employment/welfare and require progressively larger net government expenditures on the subsidies, for a given upper bound on earnings inequality. Once a critical level of each subsidy is exceeded, it is no longer self-financing. ${ }^{63}$ Furthermore, for our model, the self-financing constraint becomes binding before employment/welfare begins to decline or inequality begins to increase. Thus, the critical subsidy level identifies the magnitude of the subsidy that is maximally effective, i.e. it creates maximal employment/welfare while remaining AWE. For a variety of employment subsidies, differing in terms of their target groups, the maximal employment effects of AWE policies may be calculated, and the subsidies may be ranked on this basis.

In the context of our labor market model, calibrated for Germany, we have shown that lowwage subsidies (targeted at low-income/ability workers) are not AWE, i.e. no positive low-wage subsidies are self-financing. By contrast, hiring vouchers can be AWE. Our calibrated model lead to an unambiguous ranking of these hiring vouchers: hiring subsidies for the long-term

\footnotetext{
${ }^{62} \mathrm{An}$ increase in the net government budgetary allocation for the employment subsidy would naturally also require such an sacrifice, in an intertemporal sense.

${ }^{63}$ Of course, the critical level can be zero, in which case the subsidy is never self-financing.
} 
unemployed are more effective than hiring vouchers for low-income/ability workers. The same ranking, in terms of employment, holds for employment subsidies financed through government expenditures extending beyond the AWE limit.

While these results are striking, it is worth emphasizing that are specific to our German calibration. Our model permits an analysis of the determinants of AWE policies. Thus it provides a groundwork for future research comparing employment subsidies in different countries.

\section{References}

Bell, Brian D., Blundell, Richard W., and van Reenen, John (1999), Getting the Unemployed Back to Work: the Role of Targeted Wage Subsidies, International Tax and Public Finance, Vol. 6, No. 3, pp. 339-360.

Blanchard, Olivier, and Diamond, Peter (1989), The Beveridge Curve, Brookings Papers on Economic Activity, Vol. 1, pp. 1-60.

Boone, Jan, and van Ours, Jan C. (2004), Effective Active Labor Market Policies, IZA Discussion Paper Series, No. 1335, October 2004.

Boss, Alfred (2006), Brauchen wir einen Kombilohn?, Kiel Working Paper, No. 1279, June 2006.

Bovenberg, Lans A., Graafland, Johan J., and de Mooij, Ruud A. (2000), Tax Reform and the Dutch Labor Market: An Applied General Equilibrium Approach, Journal of Public Economics, Vol. 78, No. 1/2, pp. 194-214.

Brussig, Martin, and Erlinghagen, Marcel (2005), IAT-Report 2005-02, Institut für Arbeit und Technik, 2005.

Cardullo, Gabriele, and Van der Linden, Bruno (2006), Employment Subsidies and Substitutable Skills: An Equilibrium Matching Approach, IZA Discussion Paper Series, No. 2073, April 2006.

Chen, Yu-Fu, and Funke, Michael (2003), Labour Demand in Germany: An Assessment of Non-Wage Labour Costs, CESifo Working Paper, No. 952, May 2003.

Coe, David, and Snower, Dennis J. (1997), Policy Complementarities: The Case for Fundamental Labour Market Reform, International Monetary Fund Staff Papers, Vol. 44, No. 1, pp. 1-35.

Dickens, William T., and Lang, Kevin (1988), The Reemergence of Segmented Labor Market Theory, American Economic Review, Papers and Proceedings, Vol. 78, No. 2, 129-134.

Drèze, Jacques, and Sneessens, Henri (1997), Technical Development, Competition from Low-Wage Economies and Low-Skilled Unemployment, in: Snower, Dennis, and de la Dehesa, Guillermo (eds.), Unemployment Policy: Government Options for the Labor Market, Cambridge University Press, pp. 250-277.

Fahr, René, and Sunde, Uwe (2004), Occupational Job Creation: Patterns and Implications, Oxford Economic Papers, Vol. 56, No. 3, pp. 407-435.

Fahr, René, and Sunde, Uwe (2001), Disaggregate Matching Functions, IZA Discussion Paper, No. 335, July 2001. 
Fitzenberger, Bernd, Garloff, Alfred, and Kohn Karsten (2003), Beschäftigung und Lohnstrukturen nach Qualifikationen und Altersgruppen: Eine empirische Analyse auf Basis der IAB-Beschäftigtenstichprobe, Mitteilungen für Arbeitsmarkt- und Berufsforschung, 4/2003, pp. 509-524.

Freeman, Richard B. (1995), Are our Wages Set in Beijing?, Journal of Economic Perspectives, Vol. 9, No. 3, pp. 15-32.

Grogger, Jeffrey, and Karoly, Lynn A. (2005), Welfare Reform. Effects of a Decade of Change, Harvard University Press, Cambridge, MA.

Hui, Weng-tat and Trivedi, Pravin K. (1986), Duration Dependence, Targeted Employment Subsidies and Unemployment Benefits, Journal of Public Economics, Vol.31, No.1, pp. 105-129.

Kaldor, Nicholas (1936), Wage Subsidies as a Remedy for Unemployment, Journal of Political Economy, Vol. 44, No. 6, pp. 721-742.

Katz, Lawrence F. (1998), Wage Subsidies for the Disadvantaged, in: Freeman, Richard, and Gottschalk, Peter, Generating Jobs: How to Increase Demand for Less-Skilled Workers, pp. 21-53.

Keane, Michael, P., and Wolpin, Kenneth I. (1997), The Career Decisions of Young Men, Journal of Political Economy, Vol. 105, No. 3, pp. 473-522.

Krugman, Paul (1994), Past and Prospective Causes of High Unemployment, Economic Review - Federal Reserve Bank of Kansas City, Vol. 79, No. 4, pp. 23-43.

Layard, Richard, Nickell, Stephen, and Jackman, Richard (1991), Unemployment: Macroeconomic Performance and the Labour Market, Oxford University Press.

O'Leary, Christopher J., Decker, Paul T, and Wandner, Stephen A. (2005), Cost Effectiveness of Targeted Reemployment Bonuses, Journal of Human Resources, Vol. XL, No. 1, pp. 270-279.

Ljungqvist, Lars and Thomas J. Sargent (1998), The European Unemployment Dilemma, Journal of Political Economy, Vol. 106, No.3, pp. 514-550.

Millard, Steven P., and Mortensen, Dale T. (1997), The Unemployment and Welfare Effects of Labour Market Policy, Snower, Dennis, and de la Dehesa, Guillermo (eds.), Unemployment Policy: Government Options for the Labor Market, Cambridge University Press, pp. 545-572.

Mortensen, Dale, and Pissarides, Christopher A. (2003), Taxes, Subsidies and Equilibrium Labor Market Outcomes, in: Phelps, Edmund, Designing Inclusion: Tools to Raise Low-End Pay and Employment in Private Enterprise, Cambridge University Press, pp. 44-73.

Mortensen, Dale, and Pissarides, Christopher A. (1994), Job Creation and Job Destruction in a Theory of Unemployment, Review of Economic Studies, Vol. 61, No. 3, pp. $397-415$.

N. E. R. A. (1995), OECD Wage Subsidy Evaluation, Discussion Paper, London. 
Organisation for Economic Development and Cooperation [OECD] (2006), TaxBenefit Models, update: March 2006, Paris: OECD, online source: www.oecd.org/els/ social/workincentives.

OECD (2005a), Benefit and Wages: OECD Indicators, Paris: OECD.

OECD (2005b), Employment Outlook, Paris: OECD.

OECD (2005c), Education at a Glance, Paris: OECD.

OECD (2005d), Labour Force Statistics, Paris: OECD.

Orszag, Michael J., and Snower, Dennis J. (2003a), Designing Employment Subsidies, Labour Economics, Vol. 10, pp. 557-572.

Orszag, Michael J., and Snower, Dennis J. (2003b), Unemployment Vouchers versus Low-Wage subsidies, in: Phelps, Edmund S. (ed.), Designing Inclusion - Tools to Raise Low-end Pay and Employment in Private Enterprise, Cambridge University Press, pp. 131-160.

Orszag, Michael J., and Snower, Dennis J. (2000), The Effectiveness of Employment Vouchers: a Simple Approach, German Economic Review, Vol. 1, No. 4, pp. 385-419.

Orszag, Michael J., and Snower, Dennis J. (1999), Youth Unemployment and Government Policy, Journal of Population Economics, Vol. 12, No. 2, pp. 197-213.

Orszag, Michael J. and Snower, Dennis J. (1998), Anatomy of Policy Complementaries, Swedish Economic Policy Review, Vol. 5 No. 2, pp. 303-343.

Oskamp, Frank, and Snower, Dennis J. (2006), The Effect of Low-Wage Subsidies on Skills and Employment, Kiel Working Paper, No. 1292, September 2006.

Phelps, Edmund S. (1997a), Rewarding Work: How to Restore Participation and SelfSupport to Free Enterprise, Cambridge, MA: Harvard University Press.

Phelps, Edmund S. (1997b), Wage Subsidy Programmes: Alternative Designs, in: Snower, Dennis, and de la Dehesa, Guillermo (eds.), Unemployment Policy: Government Options for the Labor Market, Cambridge University Press, pp. 206-244

Phelps, Edmund S. (1994), Low-Wage Employment Subsidies versus the Welfare State, American Economic Review, Papers and Proceedings, Vol. 84, No. 2, pp. 54-58.

Pierrard, Olivier (2005), Impacts of Selective Reductions in Labor Taxation." Applied Economics Quarterly, Vol. 51, No. 1, pp. 49-81.

Pigou, Arthur Cecil (1933), The Theory of Unemployment, London: Macmillan.

Riphahn, Regina, Thalmeier, Anja, and Zimmermann, Klaus (1999), Schaffung von Arbeitsplätzen für Geringqualifizierte, IZA-Research Report, No. 2, Bonn, July 1999.

Sachverständigenrat [SVR] (2005), Sachverständigenrat zur Begutachtung der gesamtwirtschaftlichen Entwicklung - Jahresgutachten: 2005/06, Die Chance nutzen - Reformen mutig voranbringen, December 2005, Wiesbaden.

Saint Paul, Gilles (1998), The Political Consequences of Unemployment, Swedish Economic Policy Review, Vol. 5 No. 2, pp. 259-295. 
Saint Paul, Gilles (1996), Exploring the Political Economy of Labour Market Institutions, Economic Policy, October 1996, pp. 265-315.

Saint Paul, Gilles (1995), Some Political Aspects of Unemployment, European Economic Review, Vol. 39, No. 3/4, pp. 575-582 .

Sinn, Hans-Werner, Holzner, Christian, Meister, Wolfgang, Ochel Wolfgang, and Werding, Martin (2006), Aktivierende Sozialhilfe 2006: Das Kombilohn-Modell des ifo Instituts, Sonderdruck aus ifo Schnelldienst, No. 2, January 2006.

Snower, Dennis, and Merkl, Christian (2006), The Caring Hand that Cripples: The East German Labor Market after Reunification, American Economic Review, Papers and Proceedings, Vol. 96, No. 2, pp. 375-382.

Snower, Dennis J. (1994), Converting Unemployment Benefits into Employment Subsidies, American Economic Review, Papers and Proceedings, Vol. 84, No. 2, pp. 65-70.

Statistische Ämter des Bundes und der Länder (2006), Volkswirtschaftliche Gesamtrechnungen der Länder, online source: http://www.vgrdl.de/Arbeitskreis_VGR/, date of computation: February 2006.

Statistisches Bundesamt (2006), Volkswirtschaftliche Gesamtrechnungen: Wichtige gesamtwirtliche Größen, online source: http://www.destatis.de/basis/d/vgr/vgrtab1.php

Vereshchagina, Galina (2002), Unemployment, Firm Dynamics, and Targeted Employment Subsidies, CERGE-EI, Discussion Paper, July 2002.

Warren, Ronald S. (1996), Returns to Scale in a Matching Model of the Labor Market, Economics Letters, Vol. 50, No. 1, pp. 135-142.

Wienert, Helmut (2006), Einkommensdifferenzen zwischen Nicht-Akademikern und Akademikern, Wirtschaftsdienst, Vol. 86, No. 2, pp. 105-111.

Wilke, Ralf (2005), New Estimates of the Duration and Risk of Unemployment for WestGermany, Journal of Applied Social Science Studies, Vol. 125, No. 2, pp. 207-237.

Woodbury, Stephen, and Spiegelman, Robert G. (1987), Bonuses to Workers and Employers to Reduce Unemployment: Randomized Trials in Illinois, American Economic Review, Vol. 77, No. 4, pp. 513-530. 


\section{A Technical Appendix}

\section{A.1 Linearization}

\section{A.1.1 Firing Rate}

Non-linear equation:

$$
\phi_{\alpha}=1-\Gamma_{\alpha}\left(\frac{a_{\alpha}^{I}-w_{\alpha}+\sigma_{\alpha}-\phi_{\alpha} f_{\alpha} \delta}{1-\delta\left(1-\phi_{\alpha}\right)}+f_{\alpha}\right)
$$

where $\sigma_{\alpha}$ ist a wage subsidy for ability class $\alpha$. Linearization:

$$
\begin{aligned}
\phi_{\alpha, \text { new }}= & \phi_{\alpha, 0}-{ }_{\phi} \Gamma_{\alpha, 0}^{\prime}\left[\frac{1}{1-\delta\left(1-\phi_{\alpha}\right)}\right]_{0} \frac{1}{1+V_{\alpha}}\left[\begin{array}{c}
\left(a_{\alpha, \text { new }}^{I}-w_{\alpha, \text { new }}+\sigma_{\alpha}\right) \\
-\left(a_{\alpha, 0}^{I}-w_{\alpha, 0}\right)
\end{array}\right] \\
& -{ }_{\phi} \Gamma_{\alpha, 0}^{\prime}\left[\frac{-\phi_{\alpha} \delta}{\left(1-\delta\left(1-\phi_{\alpha}\right)\right)}+1\right]_{0} \frac{1}{1+V_{\alpha}}\left(f_{\alpha, \text { new }}-f_{\alpha, 0}\right)
\end{aligned}
$$

with

$$
V_{\alpha}={ }_{\phi} \Gamma_{\alpha, 0}^{\prime}\left[\frac{\delta\left(f_{\alpha}(\delta-1)-\left(a_{\alpha}^{I}-w_{\alpha}\right)\right)}{\left(1-\delta\left(1-\phi_{\alpha}\right)\right)^{2}}\right]_{0}
$$

where variables with subscript " 0 " are at the old steady and variables with subscript "new" are at the new steady state.

\section{A.1.2 Hiring Rates}

Non-linear equation:

$$
\eta_{\alpha}^{S}=\Gamma_{\alpha}\left(a_{\alpha}^{E 1}-w_{\alpha}+\sigma_{\alpha}^{S}+\sigma_{\alpha}+\frac{\delta\left(1-\phi_{\alpha}\right)\left(a_{\alpha}^{I}-w_{\alpha}+\sigma_{\alpha}\right)-\phi_{\alpha} f_{\alpha} \delta}{1-\delta\left(1-\phi_{\alpha}\right)}-h_{\alpha}\right),
$$

where $\sigma_{\alpha}^{S}$ is the hiring voucher for short-term unemployed workers of ability class $\alpha$.

Linearization:

$$
\begin{aligned}
\eta_{\alpha, \text { new }}^{S}= & \eta_{\alpha, 0}^{S}+{ }_{\eta} \Gamma_{\alpha, 0}^{\prime}\left[\left(a_{\alpha, \text { new }}^{E 1}-w_{\alpha, \text { new }}+\sigma_{\alpha}^{S}+\sigma_{\alpha}\right)-\left(a_{\alpha}^{E 1}-w_{\alpha, 0}\right)\right] \\
& +{ }_{\eta} \Gamma_{\alpha, 0}^{\prime}\left[\frac{\delta\left(1-\phi_{\alpha}\right)}{1-\delta\left(1-\phi_{\alpha}\right)}\right]_{0}\left[\left(a_{\alpha, \text { new }}^{I}-w_{\alpha, \text { new }}+\sigma_{\alpha}\right)-\left(a_{\alpha, 0}^{I}-w_{\alpha, 0}\right)\right] \\
& -{ }_{\eta} \Gamma_{\alpha, 0}^{\prime}\left[\frac{\phi_{2} \delta}{1-\delta\left(1-\phi_{2}\right)}\right]_{0}\left(f_{\alpha, \text { new }}-f_{\alpha, 0}\right) \\
& -{ }_{\eta} \Gamma_{\alpha, 0}^{\prime}\left(h_{\alpha, \text { new }}-h_{\alpha, 0}\right) \\
& +{ }_{\eta} \Gamma_{\alpha, 0}^{\prime}\left[\frac{-\delta\left(\left(a_{\alpha}^{I}-w_{\alpha}\right)+f_{\alpha}(1-\delta)\right)}{\left[1-\delta\left(1-\phi_{\alpha}\right)\right]^{2}}\right]_{0}\left(\phi_{\alpha, \text { new }}-\phi_{\alpha, 0}\right)
\end{aligned}
$$

And equivalently for the second unemployment duration group.

\section{A.2 Ability Group Specific Numbers}

\section{A.2.1 Replacement Rate}

To calculate the replacement rate for each ability group, we used the net replacement rates from OECD (2006). To obtain ability-specific numbers, the $67 \%$ average productivity worker (APW), 
$100 \%$ APW and 150\% APW were chosen to represent the low, medium and high-ability group in our model, respectively. For simplicity, we took the unweighted average across six family types as well as over the initial period of unemployment and long-term unemployment.

\section{A.2.2 Labor Costs}

The aggregate producer wage and gross value added per worker can be obtained from Statistische Ämter des Bundes und der Länder (2006).

The aggregate producer wage is defined as the average real gross wage per employee plus social security payments. We took the 2003 values for real labor costs (50334 Euros) and gross value added (32672 Euros) since the OECD numbers which we used for further calculations were only available until this point in time.

Using the wage equation $(11)^{64}$, we calculated the average bargaining power in the economy, where the variables denote aggregate values:

$$
\begin{gathered}
w=(1-\gamma) \beta w+\gamma(a+\rho w) \\
\gamma=\frac{w-\beta w}{a+\rho w-w \beta}
\end{gathered}
$$

We obtain $\gamma=0.204$.

Ability group specific relative labor costs for Germany are calculated as follows (OECD (2005c)): High-ability workers earn 148 percent of their medium-ability counter-parts' wage and low-ability 87 percent, respectively. ${ }^{65}$ Low-ability workers' highest education level is lower secondary education, whereas it is upper secondary education or post-secondary non-tertiary education for medium-ability and tertiary education for high-ability.

Assuming that the bargaining power is the same in all ability groups and using the respective replacement rates $^{66}$ we get for each ability group $\alpha$

$$
a_{\alpha}^{I}=\frac{w_{\alpha}-\left(1-\gamma_{\alpha}\right) \beta_{\alpha} w_{\alpha}-\gamma_{\alpha} \rho w_{\alpha}}{\gamma_{\alpha}}
$$

Table 4 summarizes the relevant values.

\begin{tabular}{|l|c|c|c|c|}
\hline & low-ability & medium-ability & high-ability & aggregate \\
\hline$l_{\alpha}$ & 16.6 & 59.4 & 24 & 100 \\
\hline$w_{\alpha}$ & 26019 & 30022 & 44220 & 32672 \\
\hline$a_{\alpha}^{I}$ & 32456 & 49147 & 78563 & 50334 \\
\hline
\end{tabular}

Table 4: Relevant Labor Cost Values

\footnotetext{
${ }^{64}$ Note that all the calculations are done for $\xi=1$ in the utility function $\left(v(c)=c^{\xi}\right)$. This is without loss of generality. The model results for hiring vouchers are not affected at all by differing $\xi$, except of course for the welfare calculations, which we show for $\xi=0.5$ and $\xi=1$. However, for low wage subsidies the wage formation would be affected and thus the results would change slightly. The cross-subsidy rankings with respect are though not affected by this specification of the utility function.

${ }^{65}$ Similar relations can be found in Wienert (2006).

${ }^{66}$ Furthermore, we assumed that the firing costs are 60 percent of the labor costs, see Chen and Funke (2003).
} 


\section{A.3 Welfare of the Workforce}

The welfare $(\Omega)$ of the workforce is calculated as the sum of the utility of the workers over the various labor market states.

$$
\Omega_{t}=\sum_{\alpha} v\left(w_{\alpha, t}(1-\tau)\right) l_{\alpha} n_{\alpha}+\sum_{\alpha} \sum_{d_{u}} v\left(b_{\alpha}\right) u_{\alpha}^{d_{u}} l_{\alpha}
$$

